\title{
Evaluation of satellite precipitation products using HEC-HMS model
}

\author{
Alemshet Belayneh $^{1}$ (D) Gashaw Sintayehu ${ }^{1} \cdot$ Kibrit Gedam $^{2} \cdot$ Tirunesh Muluken $^{3}$
}

Received: 13 March 2020 / Accepted: 25 April 2020 / Published online: 18 June 2020

(c) The Author(s) 2020

\begin{abstract}
Accurate measurement of precipitation is vital to investigate the spatial and temporal patterns of precipitation at various scales for rainfall-runoff modeling. However, accurate and consistent precipitation measurement is relatively sparse in many developing countries like Ethiopia. Nevertheless, satellite precipitation products may serve as important inputs for modeling in an area with scarce field data for a wide range of hydrological applications. In this study we evaluate the high-resolution satellite rainfall products for hydrological simulation, the Climate Hazards Group Infrared Precipitation with Stations (CHIRPS) and Tropical Rainfall Measuring Mission Multisatellite Precipitation Analysis (TMPA_3B42v7) satellite rainfall products for stream flow simulation at daily temporal and $0.25^{\circ} \times 0.25^{\circ}$ spatial resolution. The study area is located in Dabus watershed, Abbay basin, Ethiopia. We applied a nonlinear power law to remove the systematic error of satellite precipitation estimates for input into HEC-HMS hydrological model for runoff generation. The performance of the satellite rainfall and hydrological model was evaluated using Nash-Sutcliffe efficiency $\left(E_{\mathrm{NS}}\right)$, coefficient of determination $\left(R^{2}\right)$, relative volume error $(\mathrm{RVE})$, and percentage error of peak flow objective functions. The result of HEC-HMS model performance revealed $R^{2}$ of $0.78, E_{\mathrm{NS}}$ of 0.69 for CHIRPS_2 and $R^{2}$ of $0.79, E_{\mathrm{NS}}$ of 0.76 for TMPA_3B $42 \mathrm{v} 7$ satellite rainfall products during calibration periods. Our result indicated that the HEC-HMS model well predicated catchment runoff for both satellite precipitation products. The study shows that the model performance was significantly improved when bias-corrected satellite rainfall input replaced than the original uncorrected satellite products. Overall, our study showed that gauge-based simulation outperformed than satellite in terms of all objective functions over the study area.
\end{abstract}

Keywords Satellite rainfall products · CHIRPS_2 $\cdot$ TMPA_3B42v7 $\cdot$ HEC-HMS $\cdot$ Bias correction $\cdot$ Ethiopia

Alemshet Belayneh

alemywu@wldu.edu; alembe29@gmail.com

Gashaw Sintayehu

gashawsintayehu774@gmail.com

Kibrit Gedam

meftihewgedam6477@gmail.com

Tirunesh Muluken

muluken.tiruneshe@gmail.com

1 Department of Water Resources and Irrigation Engineering, Institute of Technology, Woldia University, P.O. Box 400, Woldia, Ethiopia

2 Department of Hydraulic and Water Resources Engineering, Institute of Technology, University of Gondar, P.O. Box 196, Gondar, Ethiopia

3 Department of Agricultural, Economics College of Agriculture, Mekdela-Amba University, Mekdela, Ethiopia

\section{Introduction}

Precise measurement of precipitation at global and regional scale are acute for understanding the climate and hydrological cycle, simulating land surface hydrological processes, water resources management (Stage et al. 2017). As reported by Habib et al. (2014), satellite rainfall may be used as alternative database for hydrological modeling. Yet, authors also informed evaluations are subjected to random and systematic errors. Hence, these errors should be either removed or minimized before we used in hydrological model simulation.

Variations in precipitation often influenced by nonlinear relations between numerous factors like local differences of topography, the orientation of mountains and aspects (Haile et al. 2009) which clues directly to flexible discharge output (Biemans 2012) and fluctuations in water storage (Narjary and Kamra 2013). Finally, this leads to incorrect simulation results and sometimes even in wrong conclusions (Vrgut et al. 2005). Precipitation data can be collected directly 
through ground-based observations using rain gauges and weather radars (Zhang et al. 2014) and indirectly through satellites (Lopez et al. 2017). Still, ground rainfall stations in many parts of the world and most parts of Ethiopia are very sparse and unevenly distributed (Ayehu et al. 2017). Thus, precipitation estimation is unavoidably subject to error due to different factors depending on the type of measurement (Alemohammed et al. 2015). To overcome some of the above-mentioned restrictions of ground-based precipitation measurements, space-based (satellite) estimations of rainfalls provide a hopeful alternative source (Bigiarini et al. 2017). Satellite-based precipitation estimates may offer information with spatiotemporal (near-real-time) high-resolution over wide-ranging regions wherever conventional rainfall data are unusual or absent (Kidd and Huffman 2011). Since combined precipitation products mostly have more improved quality than individual data set (Xie and Xiong 2011), different emerged rainfall products (reanalysis gauge and satellite gauge) are gradually being developed (Duan et al. 2017). It is principally worth nothing that the recently released Climate Hazards Group Infra-Red Precipitation with Station data (CHIRPS_2) provides rainfall at the finest spatial resolution of $0.05^{\circ}$ and $0.25^{\circ}$ (Funk et al. 2015).

At diverse times many academics have been carried out a study to assess the performance of satellite precipitation estimates for hydrological modeling in different regions of the world including Ethiopia and indicated that high-resolution satellite rainfall products have prospective use for hydrological modeling based on their product types. Later, all the above evaluations did not include Dabus watershed of Ethiopia which is rugged in topography and have more sparsely in situ rain gauge networks. Moreover, most of the studies were limited to satellite precipitation products of early version and only event-based analysis for examples, in (Tesfaye et al. 2017). Besides, in Dabus watershed the influences of water withdrawal, land cover and climate change have not been quantified yet due to scarce precipitation data for rainfall-runoff modeling.

As a result, this study concentrates on evaluating satellite rainfall products of CHIRPS_2 and TMPA_3B42v7 estimate by using in situ rain gauge products based on their hydrological simulation result as well as identification of sensitive parameters of model outputs when calibrated and validated with input-specific satellite precipitation estimates. The HEC-HMS hydrological model was used to simulate the stream flow for both rain gauge and satellite rainfall products. Biases between satellite rainfall estimates and observed data are identified and then used to correct satellite rainfall products by using several methods, like precipitation threshold, scaling approach, power transformation, distribution transfer, precipitation model and empirical correction methods. In this study a power transformation method was applied for satellite rainfall products. For each case of bias correction steps, it was intended to match the most important statistics coefficient of variation and mean on a scale of months.

The main objective of this research is (1) to evaluate CHIRPS_2 and TMPA_3B42v7 satellite rainfall, (2) to evaluate the ability of satellite rainfall products to characterize rainfall patterns and capture the magnitude of rainfall, (3) to assess the skill of satellite rainfall products as an input into a hydrological model for stream flow simulation and (4) to evaluate the performance of HEC-HMS model using satellite and ground-based precipitation products.

\section{Description of the study area}

The Dabus River is a north-flowing tributary of the Abay River in southwestern Ethiopia. The river is known for its continuous flow even during the dry seasons, which attributes to the existence of $600-900 \mathrm{~km}^{2}$ area of a swamp and fed by several tributaries that originate from the southwestern and central parts of Wollega. The major tributaries of Dabus River are Dilla and Keshmando which covers drainage area of $21,032 \mathrm{~km}^{2}$, and it locates between $9^{\circ} 0^{\prime} 0^{\prime \prime}-11^{\circ} 50^{\prime} 0^{\prime \prime} \mathrm{N}$ latitude and $34^{\circ} 30^{\prime} 0^{\prime \prime}-35^{\circ} 58^{\prime} 40^{\prime \prime} \mathrm{E}$ longitude within the Upper Blue Nile Basin. Geographically the course defines not only part of the border between Benishangul-Gumuz and Oromia regions but also the entire shared boundary of the Assosa and Kamashe zones of the Benishangul-Gumuz region, $664 \mathrm{~km}$ from Addis Ababa, Ethiopia. The study area contains 22 Weredas with 206,000 populations which elevation is varied from 879 to $3149 \mathrm{~m}$ (Fig. 1).

\section{Data set}

\section{Meteorological precipitation products}

In this study we used in situ-based meteorological data at different timescales (precipitation, evapotranspiration, relative humidity, wind speed, temperature and solar radiation) collected from Ethiopian National Meteorological Agency (NMA), for a period of 16 years (2000-2015) from 12 station, and out of those stations, only nine stations have complete data. Dabus River stream flow data were collected from Ministry of Water and Energy (MoWE). Two satellite rainfall products CHIRPS-2 and TMPA-3B42v7 were extracted from (http://chg.geog.ucsb.edu/data/chirps/) and (https:// pmm.nasa.gov/), respectively.

\section{Satellite precipitation products}

\section{CHIRPS-2 and TMPA-3B42v7}

The Climate Hazards Group Infra-Red Precipitation with Station data (CHIRPS version 2) is a global daily, pentadal (5), monthly precipitation product, and a third-generation 
Fig. 1 Location map of Dabus watershed

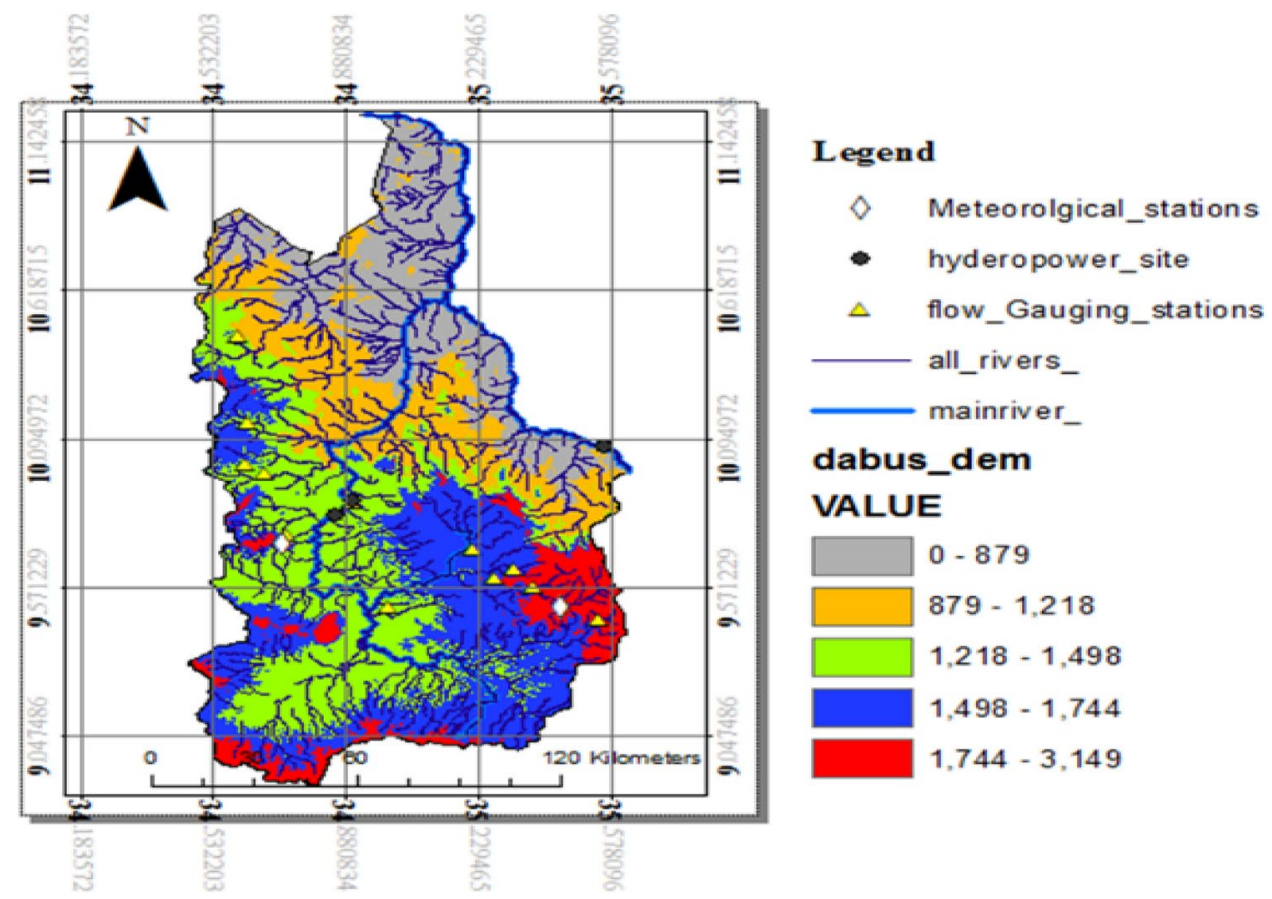

rainfall procedures clearly designed for monitoring agricultural drought and global environmental change over land (Funk et al. 2015), which was developed by the US Geological Survey and the Climate Hazards Group at the University of California, Santa Barbara, in 2015. CHIRPS_2 rainfall products mainly organized in support of drought-related issue in Africa (Climate Hazard Group 2016), principally for Ethiopia, Afghanistan or Haiti (Funk et al. 2015). CHIRPS product which belongs to the 'satellite-gauge' precipitation source category combines remotely sensed precipitation of geosynchronous and polar-orbiting satellites, from five different most recommended satellite rainfall products, with more than 2000 station records to calibrate global Cold Cloud Duration (CCD) precipitation estimates (Funk et al. 2015). The product structures at a spatial resolution of $0.05^{\circ}$ and $0.25^{\circ}$ from $50^{\circ} \mathrm{S}$ to $50^{\circ} \mathrm{N}$ across all longitudes with more than 30-year final monthly rainfall records (1981-present). The daily CCD measurements and daily CFS measurements are finally used to disaggregate the 5-daily products to daily rainfall estimates using a simple redistribution method which data are available at: http://chg.geog.ucsb.edu/data/ chirps/ with resolution of $0.05^{\circ}$ and $0.25^{\circ}$.

The Tropical Rainfall Measuring Mission (TRMM) Multisatellite Precipitation Analysis (TMPA) is a joint US and Japan satellite mission, which was launched in 1997 to monitor tropical and subtropical precipitation data and to estimate its related latent heating covering the latitude band $50^{\circ} \mathrm{N}-50^{\circ} \mathrm{S}$. It also intended to provide a best estimate of quasi-global precipitation data from a wide variety of modern satellite-born rainfall-related sensors. Its rainfall estimates are provided at relatively high spatial resolution $\left(0.25^{\circ} \times 0.25^{\circ}\right)$ and 3-hourly time stapes, in both real and postreal time to meet a wide range of research needs. The latest version of TMPA_3B42v7 rainfall product was released in June 2012, and recent studies indicated that 3B42v7 estimates improve upon 3B42v6 (Bigiarini et al. 2017; Chen et al. 2013). Nowadays, after more than 17 years of data collection, the instruments turned off on April 8, 2015, after the spacecraft exhausted its fuel reserves and replaced by Global Precipitation Measurement (GPM) mission. For this thesis work TMPA_3B42v7 daily data were used and can be easily accessed from (https://pmm.nasa.gov/).

\section{Materials and methods}

\section{Rainfall}

The Dabus watershed has three different seasons: a raining summer (June to September). For this study area about (70-90)\% of total rainfall occurs during this season which is also characterized by minimum levels of sunshine and high relative humidity. A dray season lasts from October to February characterized by maximum sunshine and low relative humidity. Minor rainy season (Belg) lasts from March to May. In general, the study area falls within the climatic classification of Tropical Climate I according to Copen-Geiger-Pohl system with uni-modal rainfall distribution. The average monthly rainfall distribution in the study area is shown in Fig. 2. 


\section{Temperature}

The maximum and minimum temperature in the watershed varies between $17-33{ }^{\circ} \mathrm{C}$ and $10-18{ }^{\circ} \mathrm{C}$, respectively. The average monthly maximum and minimum temperature in the study area is shown in Figs. 3 and 4, respectively.

\section{Stream flow}

Dabus is one of the main rivers which contribute a significant amount of flow to Upper Blue Nile basin. Due to this reason, the Ethiopian Ministry of Water Resources installed gauging station at the downstream of the river and it has long-term daily observations since 1976. Based on the recorded data from 2000 to 2015 the watershed has an
Fig. 2 Average monthly rainfall distribution of the study area (2000-2015)
Fig. 3 Average maximum monthly temperature of the study area (2000-2015)
Fig. 4 Average minimum monthly temperature of the study area (2000-2015)
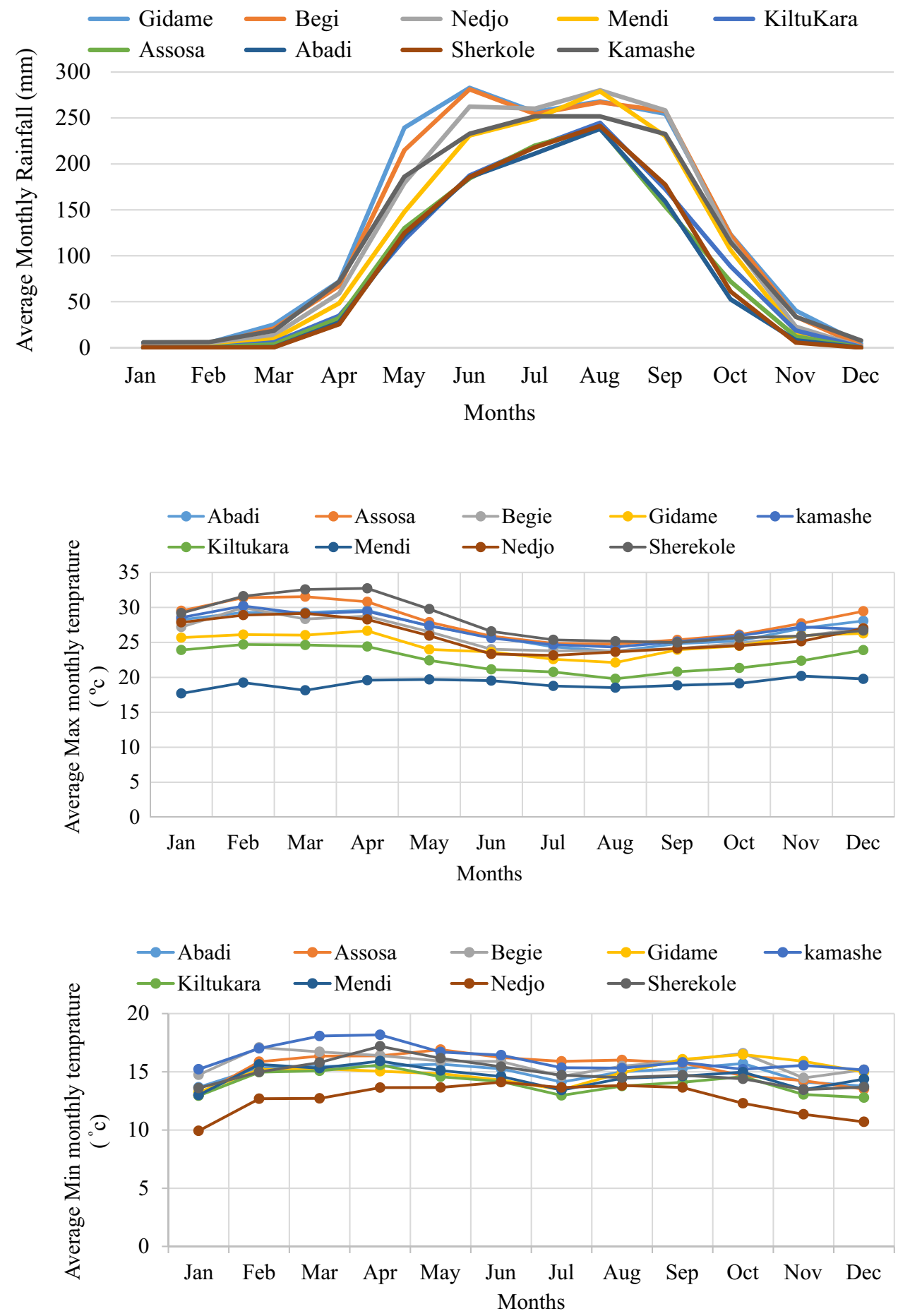
average annual daily flow of $161 \mathrm{~m}^{3} / \mathrm{s}$. The monthly average discharge at Dabus watershed gauging station is shown in Fig. 5.

\section{Land use land cover}

The land cover of the Dabus watershed is mainly characterized by woodlands, and relatively small part of the sub-basin is cultivated. Based on the National Land Use Land Cover Data (NLCD) classification, the watershed is covered by cultivated agricultural land, grass land, wet land, water bodies and forest land. The sources of land use land cover data are MoWIE and FAO land use data set 2013 with grid resolution 30 arc seconds $(1 \mathrm{~km} \times 1 \mathrm{~km})$ which was extracted from http://www.fao.org/news/story/en/item/216144/icode / or http://www.fao.org/geonetwork) (Fig. 6).

\section{Soil}

The Dabus watershed contains different soil classes; however, the most common soil types are Hablic Alisols, Hablic Nitisols, Rhodic Nitisols and Eutric Fluvisols. The sources of soil data are FAO land use data set 2013 with grid resolution 30 arc seconds $(1 \mathrm{~km} \times 1 \mathrm{~km})$ which was extracted from FAO, HWSD (Harmonized World Soil data) data set (org/ soils-portal/soil-survey/soil) and MoWIE (Fig. 7).

\section{Data set}

In order to calibrate and validate the HEC-HMS hydrological model, different input data such as hydrological, meteorological and geospatial data including stream flow, rainfall, land use land cover, DEM and soil data are required. The existing observed meteorological and hydrological data were collected from various sources. The meteorological data set such as rainfall, maximum temperature, minimum temperature, wind speed and relative humidity was collected on a daily timescale from the Ethiopian National Meteorological Agency (NMA) for a period of 2000-2015. The precipitation data set used for simulation of the HEC-HMS hydrological model in the study area has been obtained from in situ rain gauge, Tropical Rainfall Measuring Mission (TRMM) and Climate Hazards Group Infra-Red Precipitation with Station data (CHIRPS).

Fig. 5 Monthly average discharge of Dabus gauging station (2000-2015)

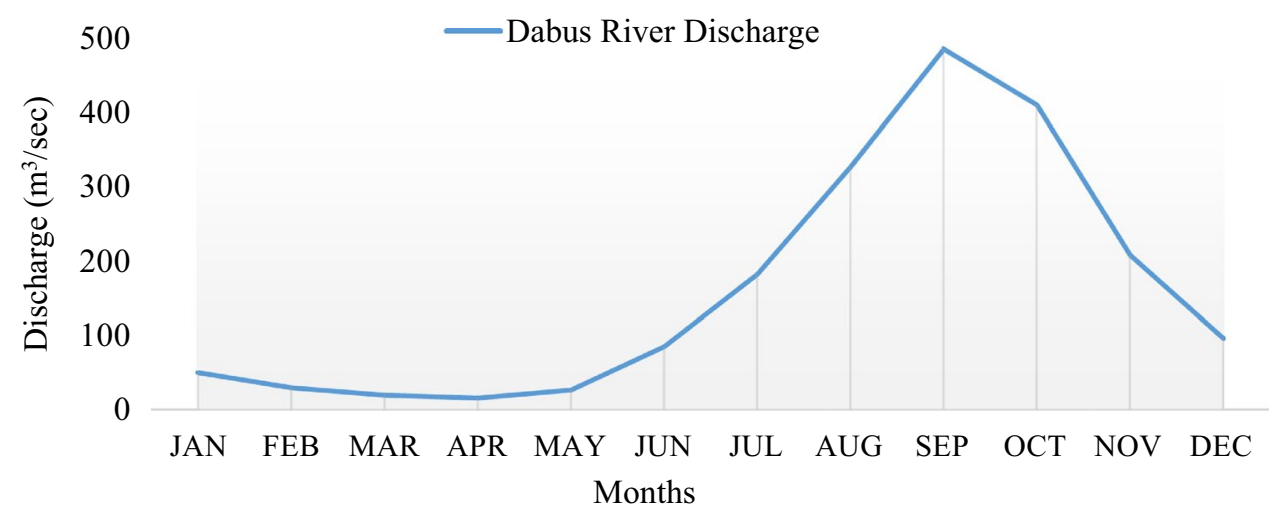

Fig. 6 Land use land cover map of the study area

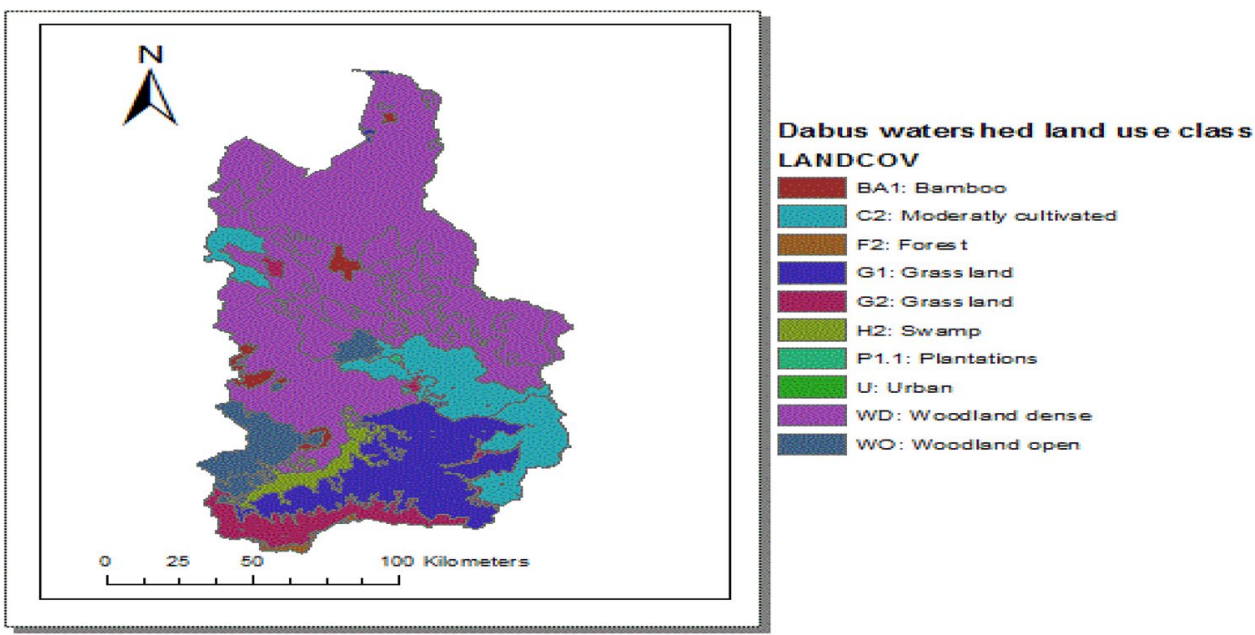


Fig. 7 Soil map of the study area

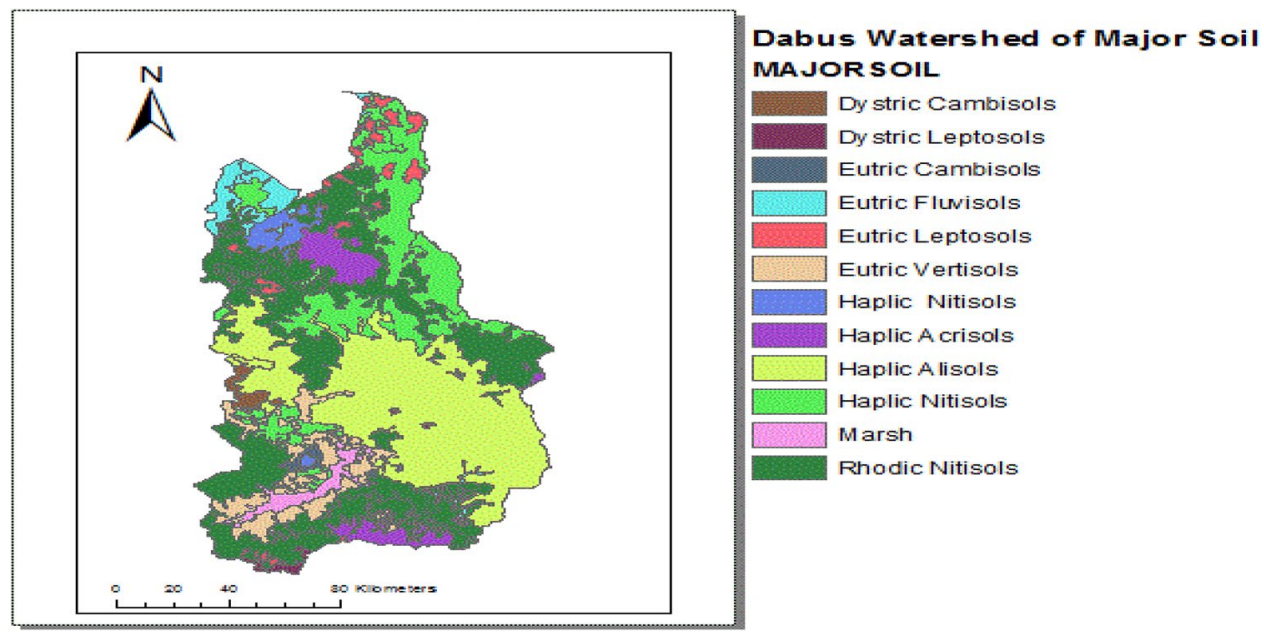

\section{Data analysis}

After collecting the essential information, filling the missing data and checking the quality of the hydrometeorological data is needed. The percentage of missing data within the time series of each hydrological and meteorological variable was evaluated. Missing of different data may be results from lack of appropriate records, shifting of station location and processing. In this study, inverse distance weighting (IDW) was applied for filling the missing data. IDW estimation is more subjective by neighboring measurements than far-away measurements.

$P(x)=\sum_{i=1}^{n} \frac{w_{i} p_{i}}{\sum_{i} w_{i}}$

where $w_{\mathrm{i}}=\frac{1}{d i^{n}}, n$ is the number of neighboring stations, $d$ is the distance between station with missed data to that of nearby station having data, $P$ is recorded data in the nearby, $P(x)$ is station with missed data and $i$ is station identification. Additionally, the quality of stream flow and rainfall data also was evaluated.

\section{Checking homogeneity of meteorological station}

Homogeneity analysis is used to identify a change in the statistical properties of time series data which is caused by either natural or man-made factors. For this study the optional recommended method to apply homogeneity has been tested with respect to neighboring stations. The none dimensionalizing of the month's value is carried out as;

$P_{i}=\frac{\overline{P_{1}}}{\bar{P}} \times 100 \%$

where $P_{i}=$ none-dimensional value of precipitation for month i, $\bar{P}_{i}=$ over year averaged monthly precipitation at the station, $\mathrm{i}$, and $\bar{P}=$ the over year average yearly rainfall of station (Fig. 8).

As shown in the above figure the maximum precipitation occurs between May and September in all station which shows the homogeneity of the stations.

\section{Checking consistency of meteorological stations}

In the process of checking recording of the in situ rain gauge stations has undergone a significant change during the period of record with various reasons; inconsistency would arise in the precipitation data of the station. This inconsistency of the recorded data for this study was done by the double mass curve technique (Fig. 9).

The graph of cumulative data of one variable verses the cumulative data of related variable is almost straight line so long as the relation between the variable is fixed ratio. Accordingly the nine meteorological stations selected for this study were consistent since the graph of the plot forms straight line without break.

\section{Stream flow homogeneity test}

Rainbow is a software tool designed to study agrometeorological and hydrological records by means of a frequency analysis and to test the homogeneity of the records. It offers a test of stream flow homogeneity, which is based on the cumulative deviations from the mean.

$\mathrm{Sk}=\sum_{i=1}^{k}(x i-\bar{x})$

where $x_{i}$ are the records from the series $x_{1}, x_{2} \ldots x_{\mathrm{n}}$ and $\bar{x}$ is the mean of the records. To test the homogeneity (uniformity) of data set, the cumulative deviations are often rescaled. When the deviation cross one of the horizontal lines the homogeneity of the data set is rejected with, respectively, 
Fig. 8 Homogeneity test for the selected nine stations in the study area

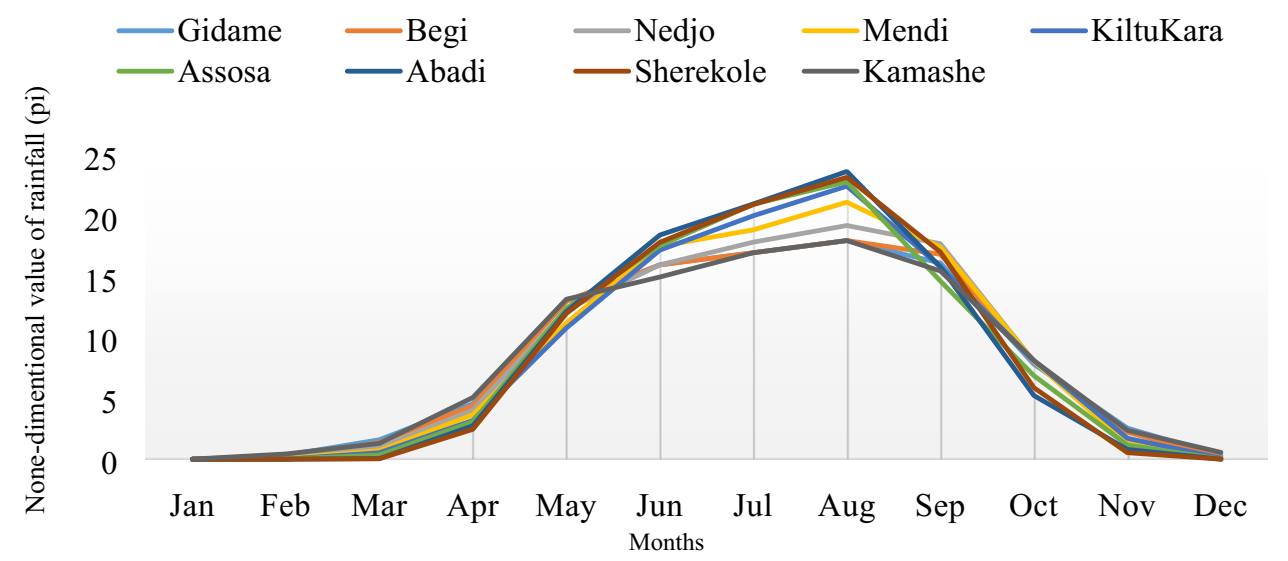

Fig. 9 Double mass curves for the selected meteorological stations

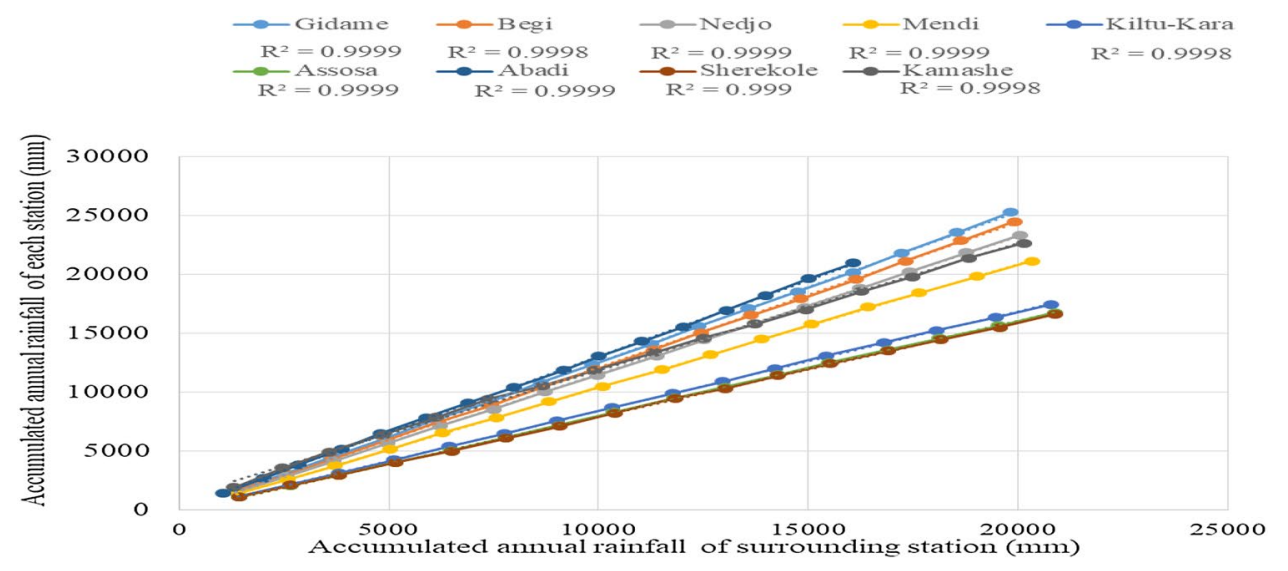

90, 95 and 99\% probability. As presented in Fig. 10 the rescaled cumulative deviations from the mean would not crossed one of the horizontal 90, 95 and 99\% probabilities lines. Therefore, for these studies the range of cumulative deviation could not be rejected on $90 \%, 95 \%$ and $99 \%$ probability levels which show the homogeneity of the annual data series and assures that the observations are almost from the same population.

\section{Processing of satellite rainfall products}

The satellite rainfall products used in this study were acquired on a Network Common Data Form (NetCDF) gridded format from January 1, 2000, to December 31, 2015. These files create a URL list which was saved to specific location on the local computer as 'myfile.nc' (NetCDF file extension). Then, in order to extract the rainfall data for the study area and to export the data into excel for each pixel, Panoply NetCDF data viewer was used. Panoply is a graphical visualization tool which is capable to produce twodimensional plots of geographically referenced data. It can plot longitude-latitude arrays as global or regional maps, plot zonal average curves of longitude-latitude statistics, combine two sets of data by differencing, summing or averaging and use a variety of 40 color tables and over 75 map projections. Most applications within panoply deal Net-CDF file format. Statistical indices like mean, standard deviation and coefficient of variation were used for evaluating the performance of the selected satellite precipitation products besides in situ rain gauge measurements. This helps to get an overall impression of the performance of the selected satellite rainfall estimates in the study periods and area.

\section{Bias correction of satellite rainfall products}

The term bias correction describes the process of scaling climate model output in order to justification for systematic errors in the climate models. The basic principle is that biases between satellite rainfall estimates and observed data are identified and then used to correct satellite rainfall products by using several methods.

Like, precipitation threshold, scaling approach, power transformation, distribution transfer, precipitation model and empirical correction methods, in this study, a power transformation method was applied for satellite rainfall products. For each case of bias correction steps, it was intended to 


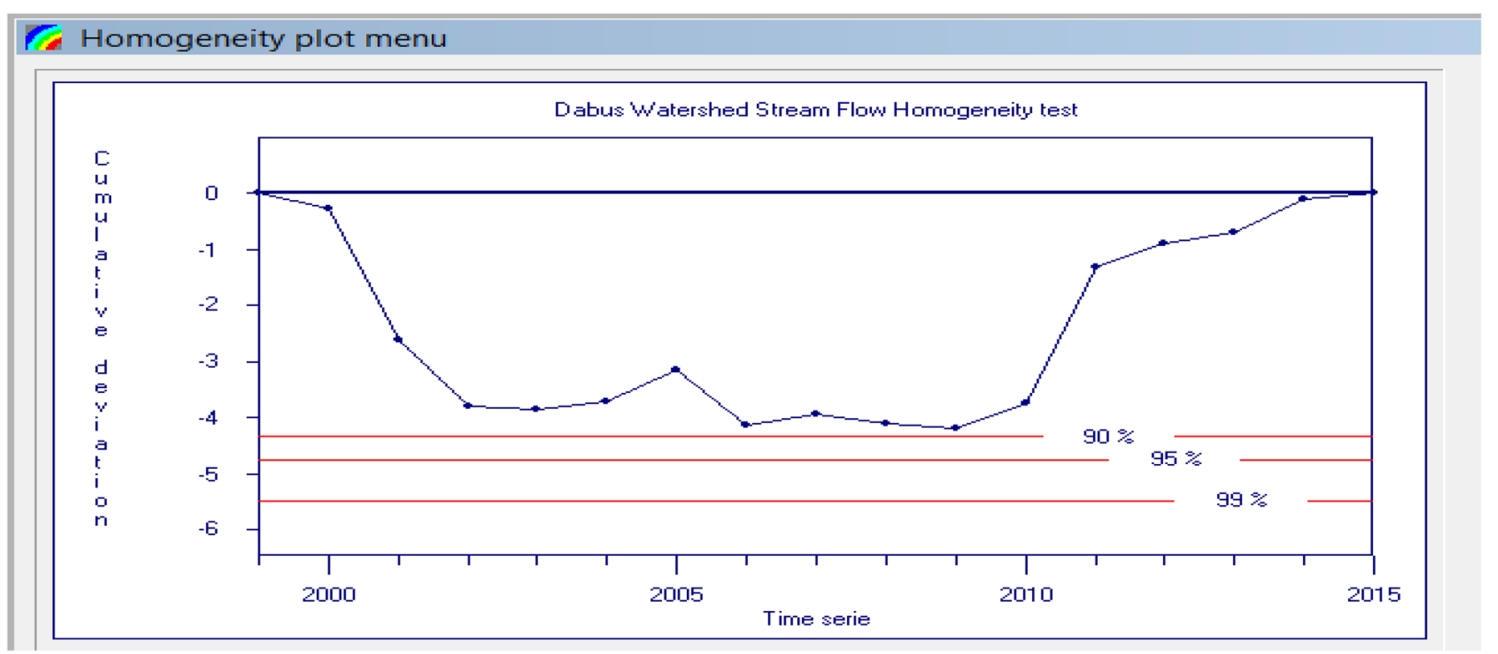

Fig. 10 Rescaled cumulative deviations from the mean for the total annual stream flow of Dabus gauging station

match the most important statistics (coefficient of variation and mean) on a scale of months.

Because the bias in precipitation was found to vary spatially, bias corrections were carried out for the whole study area based on areal data. Leander and Buishand (2007) were used a power transformation method, to correct the $\mathrm{CV}$ (coefficient of variation) and the mean of rainfall data. In this nonlinear correction method each daily precipitation amount $\mathrm{P}$ is transformed to a corrected $P^{*}$ using:

$P^{*}=a \times P^{b}$

The determination of the ' $b$ ' parameter is done iteratively. It was determined such that the $\mathrm{CV}$ of the corrected daily satellite rainfall matches the $\mathrm{CV}$ of the observed daily rainfall. In this way, the $\mathrm{CV}$ is only a function of parameter $\mathrm{b}$ according to: $\mathrm{CV}(P)=$ function $(b)$; then, the parameter ' $a$ ' is determined such that the mean of the transformed daily values matches with the mean of observed rainfall data. The resulting parameter ' $a$ ' depends on value of ' $b$,' whereas the parameter $b$ depends only on the $\mathrm{CV}$ and is independent of the value of parameter ' $a$.' Finally in order to compare performance of satellite and gauge rainfall data both should be the same in terms of spatial resolution. To do this the point data of gauge rainfall products were changed into areal rainfall data by using Thiessen polygon method.

\section{Models setup}

\section{HEC-GeoHMS input terrain preprocessing}

HEC-GeoHMS is a set of ArcGIS tools specially designed to process geospatial data and create input file for HECHMS hydrological model. Input data to HEC-HMS can be preprocessed using HEC-GeoHMS under GIS environment. In this study, HEC-GeoHMS and Arc-Hydro were used to develop river network of the watershed, to delineate subbasins, and other watershed features that co-operatively describe the drainage patterns from the digital elevation model (DEM) of the basin. Figure 11 shows the Dabus watershed which was prepared using HEC-GeoHMS. Thus the total number of Dabus watershed was divided into 5 (five) sub-basins, depending on gauging station and large river meeting place with their basin characteristics.

\section{HEC-HMS model components}

HEC-HMS model has four model components: basin model, meteorological model, control specification and input data (time series data, paired data and gridded data) components. The basin model contains information relevant to the physical attributes of the model, such as basin areas and river reach connectivity. Correspondingly, the meteorological model holds information related to rainfall data. The control specifications section comprises information related to the timing of the model such as when a storm happened and what type of time interval (second, minute, hour or day), want to use in the model. Finally, the input data component contains parameters or boundary conditions for basin and meteorological models. The main input data used for this study were satellite and in situ precipitation, observed stream flow and different basin characteristics (curve number, soil, LULC) resulting from HEC-GeoHMS process.

\section{HEC-HMS model calibration and validation}

Calibration Model calibration is a systematic process of changing model parameter values until model results match 
Fig. 11 HEC-HMS basin model representation of Dabus watershed

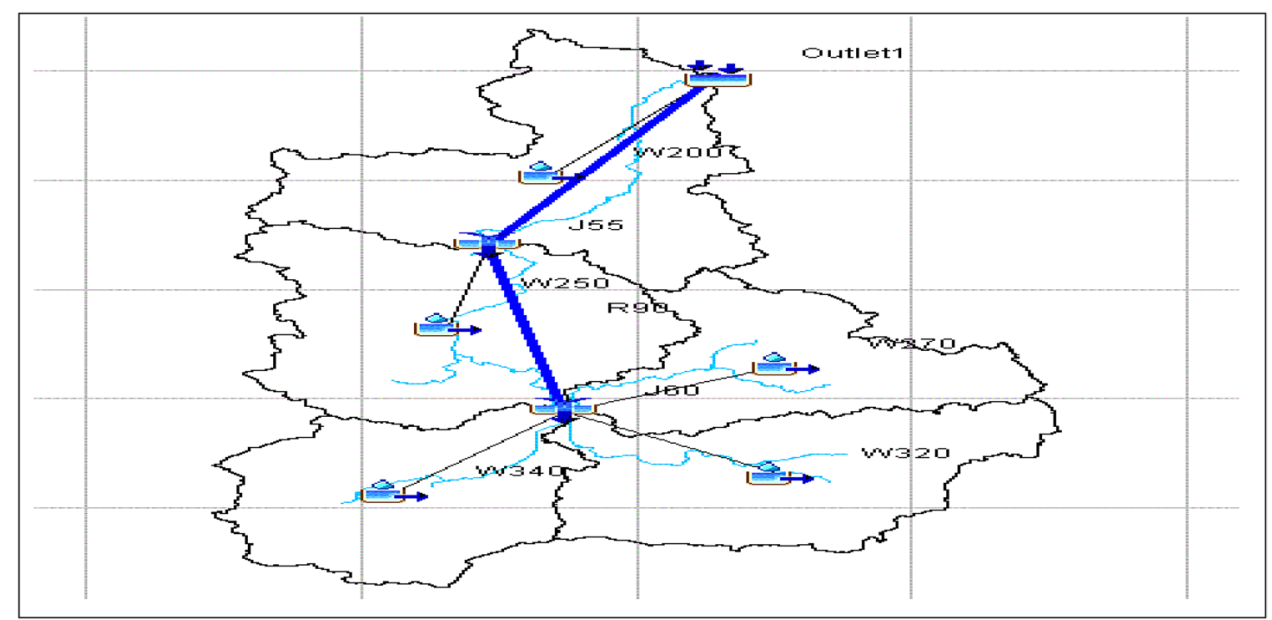

acceptably the observed data. Calibration can be achieving in terms of either manual or automated. Further, the calibration estimates some model parameters that cannot be estimated by observation or measurement or have no direct physical meaning. This study used combination of manual and automated calibration method.

Validation Model validation is the process of testing model capability to simulate observed data other than used for the calibration, with acceptable accuracy. Throughout this process, calibrated model parameters are not subject to adjustment, and their values are kept constant. Generally, in this thesis the model was calibrated for 10 years (2001-2010) and one-third of out of total time series data from (20112015) were used for validation. Additionally, 1-year time series data (2000) were used to initialize (warming-up) the model.

\section{Description of HEC-HMS model calibration and validation} methods In SCS unit hydrograph method $37.5 \%$ of the runoff volume occurs before the peak flow, and the time base of hydrograph is five times the lag time (HEC-HMS user manual 2008). The SCS developed a correlation between the time of concentration $\left(T_{\mathrm{c}}\right)$ and the lag time $\left(T_{\mathrm{lag}}\right)$. The time of concentration can be estimated based on magnitude of the event and sub-basin characteristics including topography and the length of the reach (Kirpich's formula).

$T_{\text {lag }}=0.6 \times T_{\mathrm{c}}$

Time of concentration is quasi-physically based parameter that can be estimated as,

$T_{\mathrm{C}}=t_{\text {sheet }}+t_{\text {shallow }}+t_{\text {channel }}$

where $T_{\mathrm{C}}$ is time of concentration in $\mathrm{hr}, t_{\text {sheet }}$ sum of travel of time sheet flow segment, $t_{\text {shallow }}=$ sum of travel time in shallow segment and $t_{\text {channel }}=$ sum of travel time in channel.
In recession method, relationships of $Q_{\mathrm{t}}$ the base flow at any time $t$, to an initial value are related as:

$Q_{\mathrm{t}}=Q_{\mathrm{O}} \times K^{\mathrm{t}}$

where $Q_{\mathrm{t}}$ is the base flow at time $t ; Q_{\mathrm{O}}$ is initial base flow (at time zero); and $K$ is an exponential decay constant, defined as the ratio of base flow 1 day earlier.

Muskingum simulation routes the water through the reaches by combining parameters of ' $k$ ' and ' $x$.' $K$ is the travel time of a flood wave passing through the reach, $x$ is a measure of the degree of storage varied from ( 0 to 0.5$)$, in which $x=0$ means a level-pool reservoir or maximum storage, $x=0.5$ means a pure transmission reach in which there are no storing effects. The value of $\mathrm{k}$ can be estimated as:

$K=\frac{L}{V}$

where $L$ is length of reach (m) and $V$ is mean velocity $(\mathrm{m} / \mathrm{s})$. The value of $k$ was first fixed by assuming velocity. In this study, to model the runoff process in each sub-basin and reach it was required to establish initial values of nine parameters like initial discharge, ratio to peak, recession constant, initial abstraction, constant flow rate, constant fraction, Muskingum k, Muskingum $x$, Muskingum subreach, and some parameters were imported from the basin model like basin lag and curve number.

\section{Sensitivity analysis}

Sensitivity analysis is a method to determine which parameters of the hydrological model have the highest impact on the model result. It ranks model parameter based on their influence to the overall error in the model predictions. The most sensitive parameters correspond to greater change in output response which information is vital during model calibration. According to Hann (2002) sensitivity analysis can 
be local or global. In the local sensitivity analysis, the significance of each input parameter is determined separately by keeping other model parameters constant. In the global sensitivity analysis all model inputs are allowed to vary over their ranges at the same time.

Hence, in this study a local sensitivity analysis was selected for assessing the event model. The final set of the parameters of the calibrated model was considered as baseline/nominal parameter set. Formerly, the model was run repeatedly with the starting point value for each parameter multiplied, in turn, by $0.2,0.4,0.6,0.8,1.2,1.4$ and 1.6 while keeping all other parameters constant at their nominal initial values. In addition to this, the hydrographs resulting from scenarios of adjusted model parameters were then compared with the baseline model hydrograph.

\section{Model performance evaluations}

The performance of model should be evaluated for the extent of its correctness, consistency and adaptability (Goswami 2005). In this study the HEC-HMS model performance was evaluated through visual examination of the simulated and observed hydrographs and through a set of objective functions that measure the goodness-of-fit between simulated and observed hydrograph. In addition to this, the model was evaluated using statistical measures to determine the quality and reliability of predictions when compared to observed values. Efficiency criteria such as Nash and Sutcliffe simulation efficiency (NSE), coefficient of determination $\left(R^{2}\right)$, percent error peak flow (PEPF), percentage (\%) error in the total runoff volume (RVE) and percentage bias (PBIAS) were used to evaluate the model performance.

NSE and $R^{2}$ were used to evaluate the model ability to reproduce the pattern of the observed hydrographs. The percent error peak flow measures the agreement between the magnitudes of observed and simulated peak values. The Nash-Sutcliffe coefficient of efficiency (NSE) is estimated by

$\mathrm{NSE}=1-\frac{\sum_{i=1}^{n}\left(Q_{\mathrm{obs}, i}-Q_{\mathrm{sim}, i}\right)^{2}}{\sum_{i=1}^{n}\left(Q_{\mathrm{obs}, i}-\bar{Q}_{\mathrm{obs}, i}\right)^{2}}$

where NSE is Nash-Sutcliffe coefficient of efficiency, $Q_{\text {obs,i }}$ is the observed discharge at the time step $i, \bar{Q}_{\mathrm{obs}}$ is the mean of the observed discharge, $Q_{\text {sim, } \mathrm{i}}$ is the simulation discharge at the time step $i$, and $\mathrm{n}$ is the number of observations. NSE ranges between $-\infty$ and 1 with $\mathrm{NSE}=1.0$ being the target value.

Values between 0.6 and 1.0 are generally viewed as acceptable level of performance, but values NSE $=0$ indicate that the mean observed value is a better predictor than the simulated value of hydrological data, which indicates unacceptable performance. As all terms are defined previously, the coefficient of determination $\left(R^{2}\right)$ is estimated by;

$R^{2}=\frac{\left[\sum_{i=1}^{n}\left(Q_{\mathrm{sim}, i}-\bar{Q}_{\mathrm{sim}, i}\right)\left(Q_{\mathrm{obs}, i}-\bar{Q}_{\mathrm{obs}, i}\right)\right]^{2}}{\sum_{i=1}^{n}\left[\left(Q_{\mathrm{sim}, i}-\bar{Q}_{\mathrm{sim}, i}\right)\right]^{2} \sum_{i=1}^{n}\left[\left(Q_{\mathrm{obs}, i}-\bar{Q}_{\mathrm{obs}, i}\right)\right]^{2}}$

The percentage error in total runoff volume (RVE) is estimated by;

$\operatorname{RVE}=\frac{\sum_{i=1}^{n}\left(Q_{\mathrm{sim}, i}-Q_{\mathrm{obs}, i}\right)}{\sum_{i=1}^{n}\left(Q_{\mathrm{obs}, i}\right)} \times 100$

The percentage (\%) error in total runoff volume (RVE) ranges between $-\infty$ and $\infty$. The model performance is very good for RVE between -5 and 5\%, but RVE between -10 and $-5 \%$ and $5-10 \%$ suggests satisfactory performance.

The percentage error of peak flow (PEPF) is estimated by:

PEPF $=100 \times\left|\frac{Q_{\text {obs }}(\text { peak })-Q_{\text {sim }}(\text { peak })}{Q_{\text {obs }}(\text { peak })}\right|$

where $Q_{\text {obs(peak) }}$ is the observed discharge, and $Q_{\text {sim(peak) }}$ is the peak simulated discharge. The evaluation range for PEPF is the same as to RVE.

The percentage of bias (PBIAS) measures the average tendency of the simulated data to be larger or smaller than their observed counterparts. The optimal value of PBIAS\% is 0 , with low-magnitude values indicating an accurate model simulation. Positive values show under estimation bias, and negative values indicate overestimation bias which can be calculated as,

PBIAS $=\frac{\sum_{i=1}^{n}\left(Q_{o, i}-Q_{s, i}\right)}{\sum_{i=1}^{n}\left(Q_{o, i}\right)} \times 100$

\section{Results and discussion}

In this unit the findings of the study were presented for each of the objectives planned in introduction part. The results were concisely discussed with reference to other previous scientific studies and range of model performance indicators.

\section{Comparisons of gauged and satellite rainfall products}

The precipitation data used in this study were obtained from in situ measurements and two satellite-based rainfall estimation products, CHIRPS_2 and TMPA_3B42v7, for a period of 16 years (2000-2015). Based on daily mean values, Begie station indicated a wider difference between 
in situ and CHIRPS_2 precipitation products when compared to other stations which is $1.074 \mathrm{~mm} /$ day followed by Abadie station with $0.866 \mathrm{~mm} /$ day. CHIRPS_2 satellite precipitation products also underestimate in Kamashe and overestimates in Begie station (Table 1).

Similarly based on mean values still, the difference is less than from CHIRPS_2 estimates, and Assosa station indicated a wider difference between in situ and TMPA_3B 42v7 rainfall products when compared to other stations which is $0.312 \mathrm{~mm} /$ day followed by Kiltukara station with $0.079 \mathrm{~mm} /$ day. TMPA_3B42v7 satellite precipitation data also underestimate in Kamashe and overestimate in Assosa station. It is noted that the difference between in situ and satellite precipitation estimates showed elevation-dependent trends, TMPA_3B42v7 satellite precipitation products showed higher difference in low elevation areas. This result is consistent with findings of (Hessels 2015). Even if CHIRPS_2 satellite rainfall result was less affected by elevation variation, it showed less difference for mountainous areas which is consistent with the findings of (Ayehu et al. 2017).

Also, coefficient of variation (CV) shows the degree of variation between satellite rainfall estimates and in situ rain gauge data, whereas standard deviation shows the measure of the spread of the rainfall estimates from the mean and less variation was observed between in situ and satellite precipitation products, which indicated the less temporal variability of rainfall estimates.

Generally, TMPA_3B42v7 satellite rainfall products showed better performances in terms of capturing the volume of annual rainfall than the CHIRPS_2 satellite precipitation products, while CHIRPS_2 satellite rainfall products showed better performance in terms of capturing the patterns of annual precipitation than TMPA_3B42v7 satellite rainfall products. The mean annual precipitation of in situ gauge, CHIRPS_2 and TMPA_3B42v7 satellite rainfall products was estimated to be $1238.621 \mathrm{~mm}, 1339.328 \mathrm{~mm}$ and $1325.787 \mathrm{~mm}$, respectively.

As Fig. 12 shows the inter-annual variation of rainfall data performs well for the inputs of in situ, TMPA_3B42v7 and CHIRPS_2 precipitation products for a period of 2000-2015. Figure 12 indicates CHIRPS_2 satellite rainfall product shows slightly overestimation and TMPA_3B42v7 satellite rainfall products show both overestimation and underestimation.

Generally, TMPA_3B42v7 satellite rainfall products showed better performances in terms of capturing the volume of annual rainfall than the CHIRPS_2 satellite precipitation products, while CHIRPS_2 satellite rainfall products showed better performance in terms of capturing the patterns of annual precipitation than TMPA_3B42v7 satellite rainfall products.

The mean annual precipitation of in situ gauge, CHIRPS_2 and TMPA_3B42v7 satellite rainfall products was estimated to be $1238.621 \mathrm{~mm}, 1339.328 \mathrm{~mm}$ and $1325.787 \mathrm{~mm}$, respectively.

\section{HEC-HMS modeling result for observed rainfall products}

\section{Sensitivity analysis}

In order to understand the effect of each model parameter, a sensitivity analysis was applied before calibration and validation of the model using HEC-HMS 4.2 graphical user interface (GUI). So, Muskingum (k), Muskingum (x), curve number $(\mathrm{CN})$, recession constant (R.C), initial abstraction (I. ab), initial discharge (I.D), ratio to peak (R.P), flow rate (F.R), constant fraction (C.F), lag time and number of subreach were included in the sensitivity analysis.

Figure 13 expressed the Nash-Sutcliffe coefficient of efficiency (NSE) for specific change in parameter values of this

Table 1 Summary statistics of daily in situ and satellite rainfalls products

\begin{tabular}{|c|c|c|c|c|c|c|c|c|c|}
\hline Stations & Rainfall type & Mean (mm) & Std.dev. & $\mathrm{CV}$ & Stations & Rainfall type & Mean (mm) & Std.dev. & $\mathrm{CV}$ \\
\hline \multirow[t]{3}{*}{ Abadie } & In situ & 6.809 & 6.992 & 1.026 & \multirow[t]{3}{*}{ Mendie } & In situ & 6.518 & 6.092 & 0.934 \\
\hline & CHIRPS & 5.943 & 7.635 & 1.285 & & CHIRPS & 5.784 & 5.347 & 0.924 \\
\hline & TMPA-3B42v7 & 6.855 & 6.757 & 0.986 & & TMPA-3B42v7 & 6.463 & 6.145 & 0.951 \\
\hline \multirow[t]{3}{*}{ Begie } & In situ & 6.813 & 6.843 & 1.004 & \multirow[t]{3}{*}{ Kamashe } & In situ & 5.725 & 5.768 & 1.007 \\
\hline & CHIRPS & 5.739 & 7.662 & 1.335 & & CHIRPS & 6.023 & 7.869 & 1.307 \\
\hline & TMPA-3B42v7 & 6.766 & 6.605 & 0.976 & & TMPA-3B42v7 & 6.706 & 6.634 & 0.989 \\
\hline \multirow[t]{3}{*}{ Kiltukara } & In situ & 5.708 & 5.817 & 1.019 & \multirow[t]{3}{*}{ Nedjo } & In situ & 6.158 & 6.891 & 1.119 \\
\hline & CHIRPS & 5.551 & 7.656 & 1.379 & & CHIRPS & 5.866 & 5.794 & 0.988 \\
\hline & TMPA-3B42v7 & 5.629 & 5.807 & 1.032 & & TMPA-3B42v7 & 6.128 & 8.763 & 1.429 \\
\hline \multirow[t]{3}{*}{ Assosa } & In situ & 6.869 & 6.921 & 1.007 & & & & & \\
\hline & CHIRPS & 6.084 & 8.517 & 1.399 & & & & & \\
\hline & TMPA-3B42v7 & 6.557 & 6.671 & 1.017 & & & & & \\
\hline
\end{tabular}


Fig. 12 Mean annual rainfall of in situ and satellite rainfall products

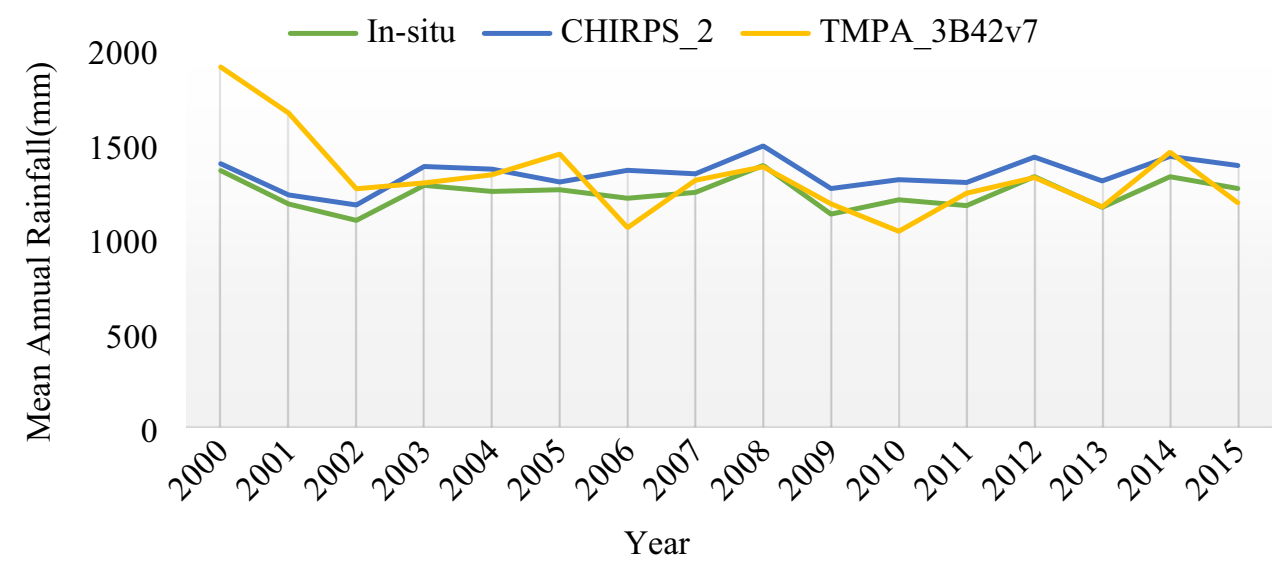

study. Based on the analysis, lag time (L.T) was ranked as the most sensitive parameter on stream flow of this study as shown by steepest slope of $E_{\mathrm{NS}}$ parameter change plot. The parameter I.ab and I.D were the second and third control effects on $E_{\mathrm{NS}}$, respectively. The remaining eight (8) parameters were not showed significant changes on value of $E_{\mathrm{NS}}$.

\section{Calibration and validation}

According to Santhi et al. (2001) model performance can be said to be very good if, $E_{\mathrm{NS}}(0.75-1), R^{2}(0.75-1)$, PBIAS $(<10) \%$; good if, $E_{\mathrm{NS}}(0.65-0.75), R^{2}(0.65-0.75)$, PBIAS $(10-15) \%$; satisfactory if, $E_{\mathrm{NS}}(0.5-0.65), R^{2}(0.5-0.65)$, PBIAS (15-25)\%; and unsatisfactory if, $E_{\mathrm{NS}}(<0.5), R^{2}$ $(<0.5)$, PBIAS $(>25) \%$.

The HEC-HMS hydrological model was calibrated in Dabus watershed for the period of (2001-2010) and validated for the period of (2011-2015) including 1 year (2000) for warming-up. Table 2 shows the fixed HEC-HMS model parameter value during automated and manual calibration of observed precipitation data.

Figure 14 shows the observed and simulated stream flow hydrograph for calibration (2001-2010) and for validation (2011-2015) period. The results indicated a good agreement between the data sets with an $E_{\mathrm{NS}}$, of 0.843 and $R^{2} 0.954$ for the calibration period and $E_{\mathrm{NS}}$ of 0.791 and $R^{2}$ of 0.952 for the validation period. The model captured well the daily time series of stream flow as well as the trend during calibration and validation periods. The results showed good performance in terms of capturing the observed stream flow volume with RVE of $5.557 \%$ during calibration and $6.634 \%$ during validation period. As the HEC-HMS model performance statistics, Table 3, shows for both calibration and validation periods (2001-2015) and on the standards set out by (Moriasi 2007), for evaluating hydrological model performance the HEC-HMS model was rated as 'good' for Dabus watershed of this study.

Furthermore, a comparison of the measure of the statistics for calibration and validation periods tells a good performance of the hydrological model during the calibration period as compared to the validation period. This thought agrees with findings of (Moriasi 2007), in which model performance during the calibration period performs best compared to the validation period. However, the model performance is still acceptable for the validation period, indicating that the HEC-HMS model can be applied to study rainfall-runoff relation in the catchments outside of the calibration period. In Fig. 14
Fig. 13 HEC-HMS model sensitivity analysis evaluated for Dabus station in terms of $E_{\mathrm{NS}}$

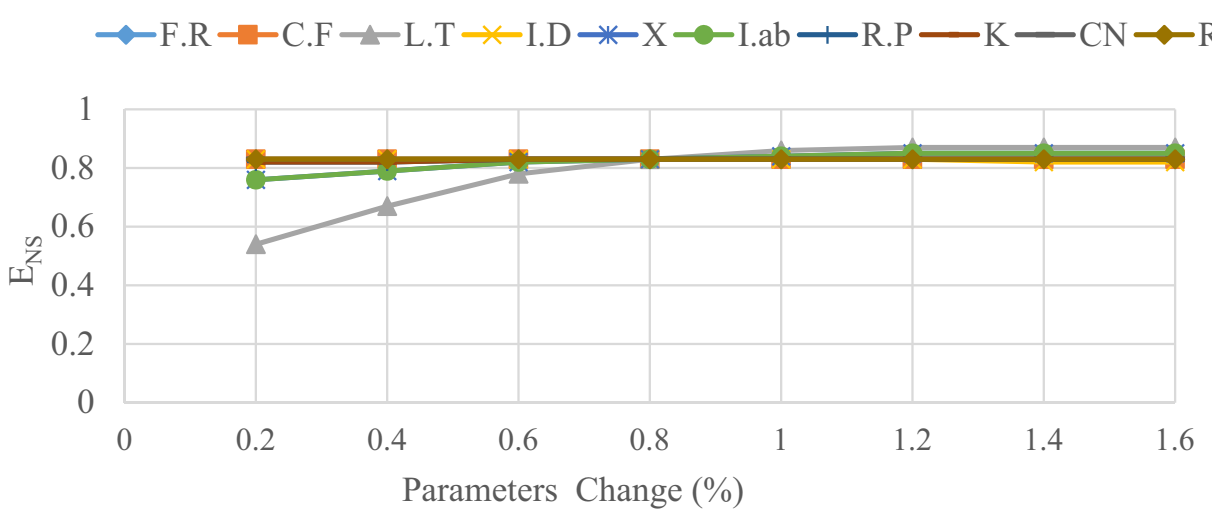


Table 2 Model Parameters selected for calibration of observed rainfall

\begin{tabular}{llllllllllllll}
\hline Element & \multicolumn{1}{l}{ Fitted parameter value } \\
\cline { 2 - 12 } & F.R. & C.F. & K & N.Sub. & L.T. $(\mathrm{min})$ & X & I.D. $\left(\mathrm{m}^{3} / \mathrm{s}\right)$ & R.C. & R.P. & CN & I.ab. \\
\hline R30 & 0.1 & 0.002 & 128 & 1 & - & 0.48 & - & - & - & - & - \\
R90 & 0.3 & 0.001 & 138 & 1 & - & 0.37 & - & - & - & - & - \\
W200 & - & - & - & - & 30000 & - & 0.59 & 0.01 & 0.001 & 35.042 & 227.4 \\
W250 & - & - & - & - & 30000 & - & 1.19 & 0.97 & 0.59 & 35.352 & 285.6 \\
W270 & - & - & - & - & 30000 & - & 213 & 0.97 & 0.93 & 35.28 & 50.06 \\
W320 & - & - & - & - & 30000 & - & 19.3 & 0.01 & 0.001 & 35.27 & 1.53 \\
\hline
\end{tabular}

where F.R flow rate; C.F constant fraction; $\mathrm{k}$ and $\mathrm{x}$ for Muskingum; N.sub: number of subreach; L.T lag time; I.D initial discharge; R.C recession constant; $\mathrm{CN}$ curve number; I.ab initial abstraction; R.P ratio to peak; R30 and R90 reach and W200-W320, sub-basins
Fig. 14 Observed and simulated daily discharge hydrograph of Dabus watershed using in situ rainfall products

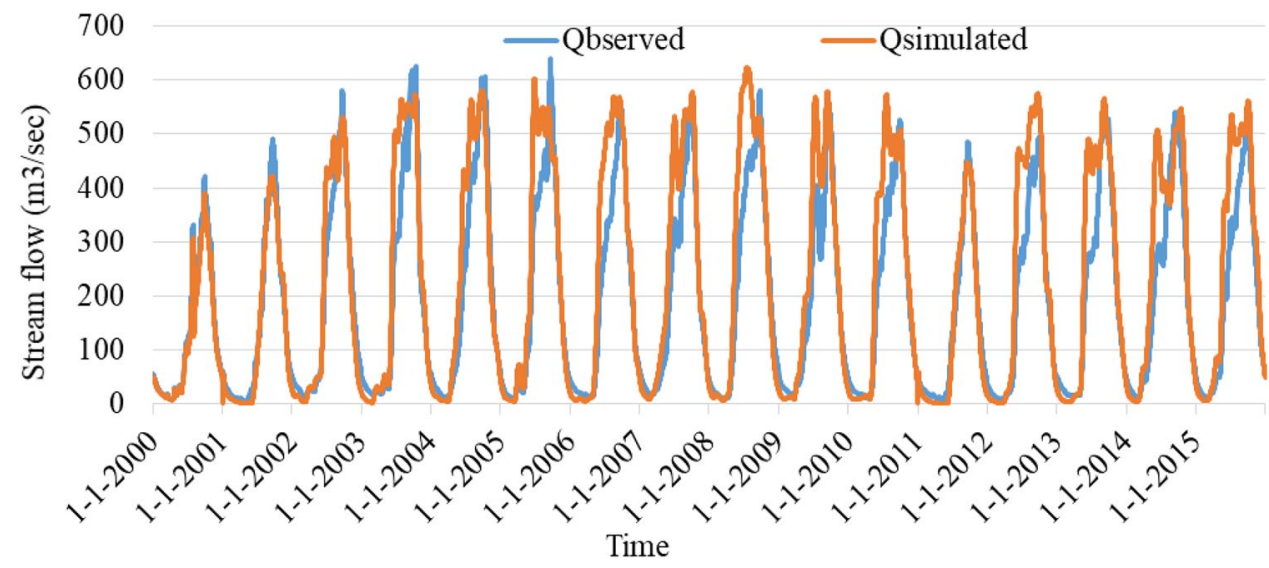

Table 3 Daily time step calibration and validation result of CHIRPS_2

\begin{tabular}{llllll}
\hline Period & \multicolumn{6}{l}{ Objective function } \\
\cline { 2 - 6 } & $E_{\mathrm{NS}}$ & $R^{2}$ & PBIAS (\%) & PEPF (\%) & RVE \\
\hline $\begin{array}{l}\text { Calibration (2001- } \\
\text { 2010) }\end{array}$ & 0.685 & 0.777 & -18.425 & 4.042 & 7.893 \\
$\begin{array}{l}\text { Validation (2011- } \\
\text { 2015) }\end{array}$ & 0.513 & 0.704 & -21.467 & -6.075 & 8.562 \\
\hline
\end{tabular}

calibration and validation results of in situ rainfall products are presented.

Although observed and simulated discharge matched well for calibration and validation periods, there was an average magnitude overestimation of the observed stream flow with PBIAS of $-14.648 \%$ for the calibration and $-19.638 \%$ for validation period. The agreement of peak magnitude between observed and simulated stream flow was very good with PEPF of $2.364 \%$ for calibration and $-6.346 \%$ for validation period as indicated in Figure 14 .

\section{HEC-HMS modeling with satellite precipitation products}

The two selected satellite precipitation products (CHIRPS_2 and TMPA_3B42v7) were used as an input for model sensitivity analysis, calibration and validation independently for the same time window.

\section{Sensitivity analysis}

The results of the sensitivity analysis for CHIRPS_2 and TMPA_3B42v7 satellite rainfall products are shown in Fig. 15. Based on the analysis, Muskingum (x) was ranked as the most sensitive parameter on stream flow as shown by steepest slope of PBIAS parameter change plot although the parameter lag time (L.T.) also affects PBIAS (\%) next to Muskingum $\mathrm{x}$.

\section{Calibration and validation of satellite rainfall products}

CHIRPS_2 A plot of daily observed to daily simulated stream flow indicated a satisfactory agreement with an $E_{\mathrm{NS}}$ of 0.685 and $R^{2}$ of 0.777 for the calibration period and with an $E_{\mathrm{NS}}$ of 0.513 and $R^{2}$ of 0.704 for CHIRPS_2 satellite 
Fig. 15 HEC-HMS model sensitivity analysis evaluated in terms of PBIAS (\%)

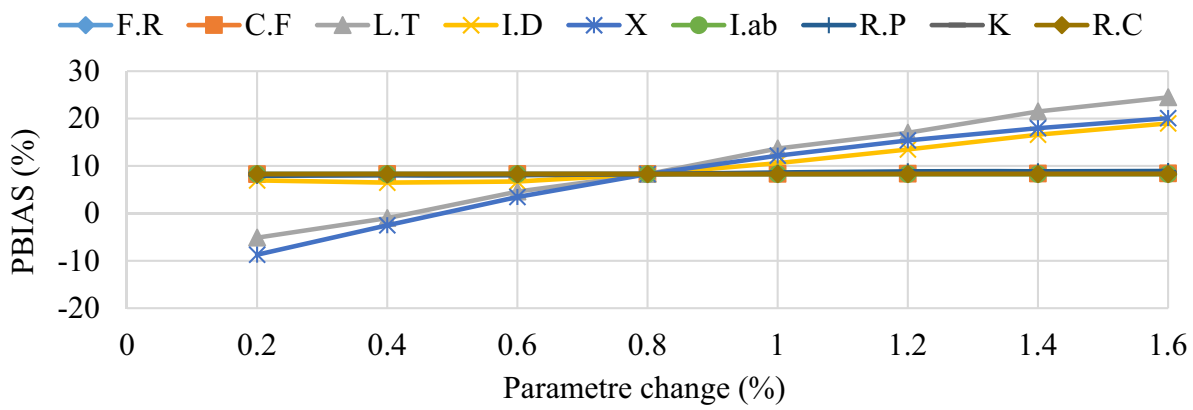

rainfall products. The model captured well the daily time series of stream flow plus the trend during both calibration and validation periods.

Even if observed and simulated outputs matched acceptably for calibration and validation periods, there was an average magnitude overestimation of the observed stream flow with PBIAS (\%) of $-18.425 \%$ for the calibration and $-21.467 \%$ for validation period. The agreement of magnitude between observed and simulated peak flow was good with PEPF of $4.042 \%$ for calibration and PEPF of $-6.075 \%$ for validation period, and the results showed satisfactory performance in terms of capturing the observed discharge volume with RVE of $7.893 \%$ during calibration and $8.562 \%$ during validation periods. Table 3 shows the calibration (2001-2010) and validation (2011-2015) results of CHIRPS_2 satellite precipitation estimates (Figs. 16, 17).

As shown in the above graphs the result of CHIRPS_2 satellite precipitation estimates for both calibration and validation period was better in capturing the patterns and peak of the rainfall. It is also clearly indicated that for high precipitation products its flow is also high. In overall, CHIRPS_2 satellite precipitation products show large error during low precipitation (dry) seasons and give best result for flat areas. This result agrees with the findings of Duan et al. (2016) and Bayissa et al. (2017), in which CHIRPS_2 satellite precipitation products show an overestimation of lower monthly precipitation products and can be used for flood monitoring and early warning system.

TMPA_3B42v7 Even if the performance of TMPA_3B42v7 precipitation result was better than CHIRPS_2, a plot of daily observed stream flow to daily simulated stream flow indicated a satisfactory agreement with an $E_{\mathrm{NS}}$ of 0.755 and $R^{2}$ of 0.786 for the calibration period and an $E_{\mathrm{NS}}$ of 0.714 and $R^{2}$ of 0.705 for validation period.

As the Table 4 and Fig. 18 show the model captured well the daily time series of stream flow as well as the trend during both in the calibration and validation periods. Even though observed and simulated outputs matched tolerably for calibration and validation periods, there was an average magnitude overestimation of the observed stream flow with PBIAS of $-11.325 \%$ for the calibration and $-17.357 \%$

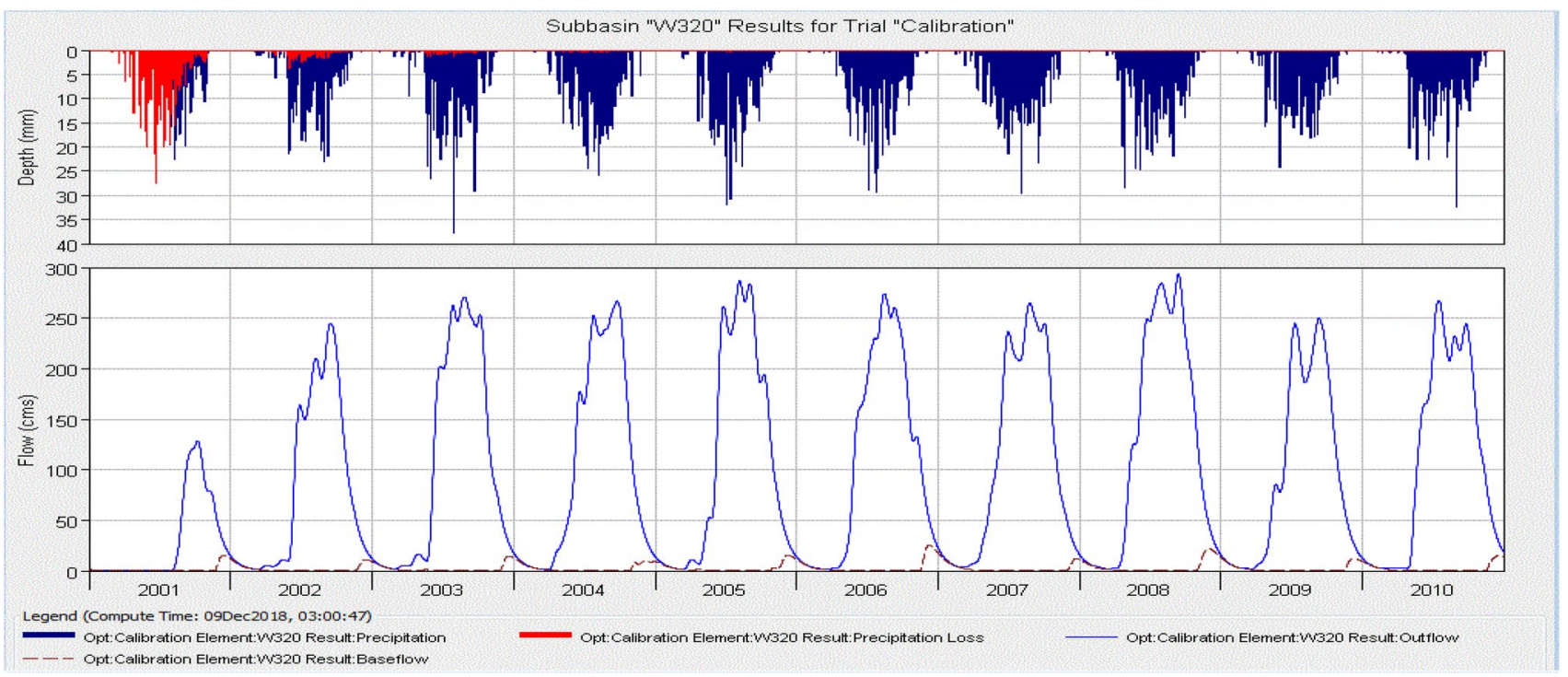

Fig. 16 Observed rainfall and simulated hydrograph of calibration at Assosa station using CHIRPS_2 satellite rainfall products 
Fig. 17 Observed and simulated daily discharge hydrograph of CHIRPS_2 products

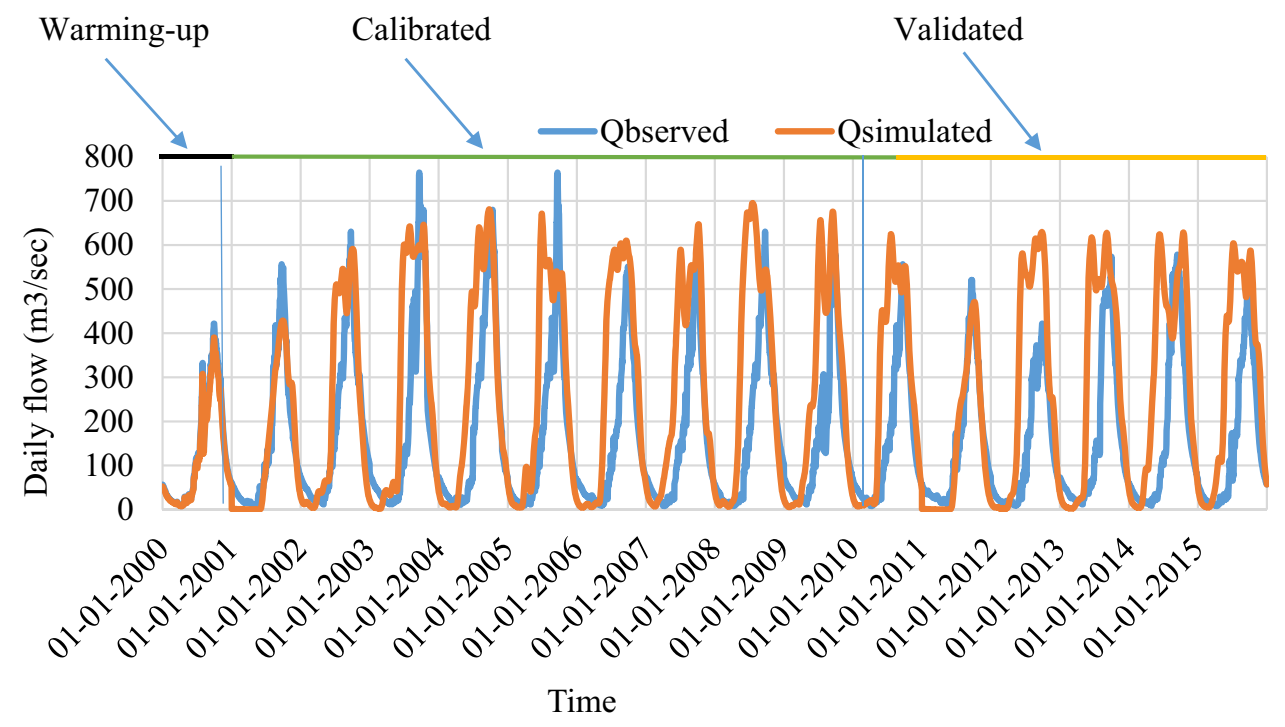

Table 4 Daily time step calibration and validation results of TMPA_3B42v7 products

\begin{tabular}{llllll}
\hline Period & \multicolumn{6}{l}{ Objective function } \\
\cline { 2 - 6 } & $E_{\mathrm{NS}}$ & $R^{2}$ & PBIAS (\%) & PEPF (\%) & RVE \% \\
\hline $\begin{array}{l}\text { Calibration } \\
\quad \text { (2001-2010) }\end{array}$ & 0.755 & 0.786 & $-11.325 \%$ & 7.335 & 9.893 \\
$\begin{array}{l}\text { Validation (2011- } \\
\text { 2015) }\end{array}$ & 0.714 & 0.705 & $-17.357 \%$ & -5.075 & 10.00 \\
\hline
\end{tabular}

for validation period. The agreement of magnitude between observed and simulated flow was satisfactory with PEPF of $7.335 \%$ for calibration and PEPF of $-5.075 \%$ for validation period, and the results showed a good performance in terms of capturing the observed stream flow volume with RVE of $9.893 \%$ during calibration and $10 \%$ during validation periods. Generally, TMPA_3B42v7 satellite rainfall product was showed good performance during wet seasons and at highlands. This thought agrees with the findings of Bigiarini et al. (2017) and Pineda et al. (2016), in which
TMPA_3B42v7 satellite rainfall products show a better correlation in higher elevation areas than lower elevation areas.

\section{Comparisons of HEC-HMS model performance for satellite rainfall products}

As clearly indicated in the above the sensitivity analysis of the selected stream flow parameters was done independently, and its comparison results showed that eleven parameters were recognized as significantly sensitive in common for both CHIRPS_2 and TMPA_3B42v7 satellite rainfall products. But the sensitive percentage of objective function value was different in each case, which indicated that the sensitivity of flow parameters was dependent on the type of satellite rainfall products used. In general, as described in the Table 4, Fig. 18 and other performance evaluation criteria, the HEC-HMS model gives better outcome when it was calibrated and validated by TMPA_3B42v7 satellite precipitation products than CHIRPS_2 satellite rainfall products for Dabus watershed area. This result is consistent with the finding of Hessels (2015), which was conducted in Blue Nile
Fig. 18 Observed and simulated daily discharge hydrograph of TMPA_3B42v7 rainfall products

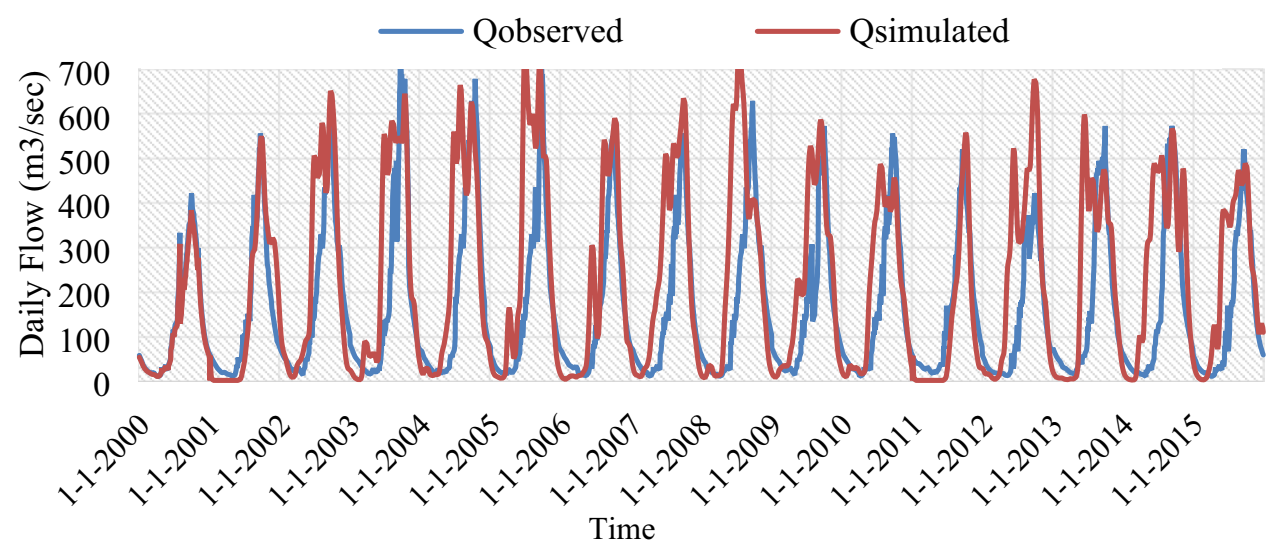


basin, Ethiopia. The results also could be due to the topography of the study area which is characterized by rugged landscape with higher elevation areas, as TMPA_3B42v7 satellite rainfall products give slightly better results than CHIRPS_2 in high elevation areas (Table 5).

\section{Comparisons of in situ and satellite precipitation products}

In this section, the comparison was made to evaluate the HEC-HMS model performance with precipitation inputs from in situ precipitation estimates and TMPA_3B42v7 satellite rainfall products which was showed relative better performance than CHIRPS_2 satellite rainfall estimates in the above section. Although the percentage of sensitivity value was different, all flow parameters were common for both in situ precipitation products and TMPA_3B42v7 satellite rainfall estimates. As showed in the above discussion, it is clear that in both model calibration and validation periods HEC-HMS model showed better performance than satellite precipitation estimates, based on the model efficiency evaluation criteria's and the capacity of simulating the stream flow. This reduction of model performance statistics might be due to the satellite rainfall estimates contaminated with random and systematic errors (Ambaw 2016; Habib et al. 2014).

\section{Effects of bias correction of satellite rainfall products}

In order to clearly understand the effect of bias correction on satellite rainfall products both the bias-corrected and uncorrected satellite precipitation estimates were used independently as model input and provided the following outputs.

In order to clearly understand the effect of bias correction on satellite rainfall products both the bias-corrected and uncorrected satellite precipitation estimates were used independently as model input, and Fig. 19 indicates that the performance of bias-corrected satellite rainfall products is better than uncorrected satellite rainfall products. But the performance of in situ rainfall products is still better than the performance of satellite rainfall products.

Table 6 and Fig. 20 clearly indicate that the model performance statistics value has been increased when the model used bias-corrected satellite rainfall products. Thus, it can be concluded that bias-corrected satellite rainfall estimates showed better performance than uncorrected satellite rainfall estimates for stream flow simulation in the study area. However, the performance of bias-corrected satellite precipitation products was less than the performance of in situ rainfall products. These thoughts were similar to the findings of (Ambaw 2016; Habib et al. 2014; Liu et al. 2014; Yong et al. 2012), in which the performance of model increases when it calibrates and validates with in situ rainfall products.

\section{Conclusions}

In this study, the HEC-HMS model with integration of GIS and HEC-GeoHMS was used and evaluated for stream flow simulation in Dabus watershed, Abbay basin Ethiopia. The hydrological and meteorological products were obtained from in situ gauging stations and satellite estimates for a period from 2000 to 2015.

Unlike other previous studies; this study was more comprehensive in using combined rain gauge and satellite rainfall estimates for the better accuracy of the result. Simulation of the study was done by using input data from satellite precipitation estimates (CHIRPS_2 and TMPA_3B42v7) and gauging station precipitation data independently. In addition to this, bias-corrected satellite rainfall estimates are also

Table 5 Summary of model performance results of CHIRPS_2 and TMPA_3B42v7

\begin{tabular}{|c|c|c|c|c|c|c|c|c|c|c|}
\hline \multirow[t]{2}{*}{ Rainfall Type } & \multicolumn{5}{|c|}{ Calibration period (2001-2010) } & \multicolumn{5}{|c|}{ Validation Period (2011-2015) } \\
\hline & $\overline{R^{2}}$ & $E_{\mathrm{NS}}$ & PBIAS (\%) & PEPF $(\%)$ & $\operatorname{RVE}(\%)$ & $\overline{R^{2}}$ & $E_{\mathrm{NS}}$ & PBIAS (\%) & PEPF $(\%)$ & RVE (\%) \\
\hline CHIRPS_2 & 0.777 & 0.685 & -18.42 & 4.042 & 7.89 & 0.704 & 0.513 & -21.46 & -6.07 & 8.56 \\
\hline TMPA_3B42v7 & 0.786 & 0.755 & -11.32 & 7.335 & 9.89 & 0.705 & 0.714 & -17.35 & -5.07 & 10.0 \\
\hline
\end{tabular}

Fig. 19 Statistical comparison of simulation of daily stream flow of various rainfall inputs

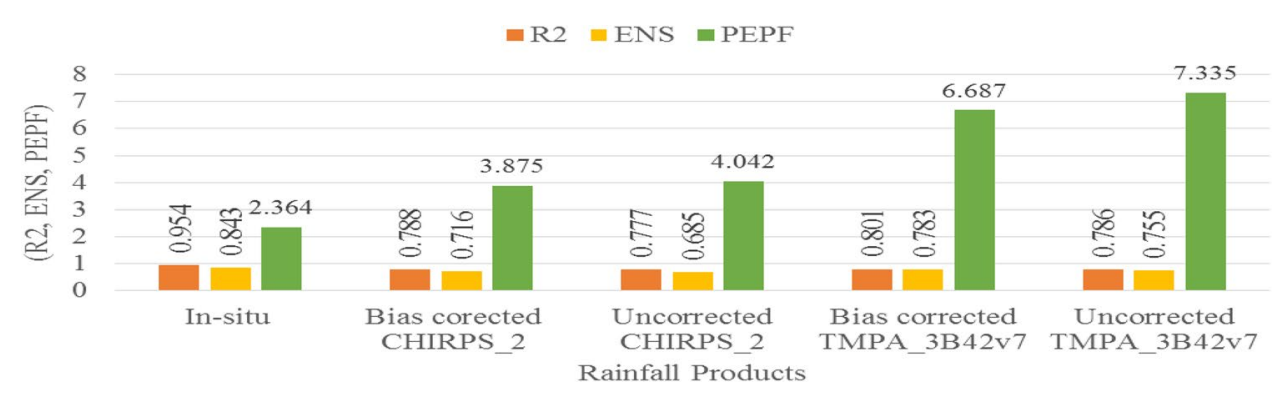


Table 6 Daily time step calibration and validation periods model performance statistics using bias-corrected satellite precipitation estimates
Fig. 20 Daily calibration results of in situ, Bias-corrected CHIRPS 2 and uncorrected CHIRPS_2 rainfall products

\begin{tabular}{|c|c|c|c|c|}
\hline \multirow[t]{2}{*}{ Performance statistics } & \multicolumn{2}{|c|}{ Calibration Period (2001-2010) } & \multicolumn{2}{|c|}{ Validation period (2011-2015) } \\
\hline & $\begin{array}{l}\text { Bias-corrected } \\
\text { CHIRPS_2 }\end{array}$ & $\begin{array}{l}\text { Bias-corrected } \\
\text { TMPA_3B42v7 }\end{array}$ & $\begin{array}{l}\text { Bias-corrected } \\
\text { CHIRPS_2 }\end{array}$ & $\begin{array}{l}\text { Bias-corrected } \\
\text { TMPA_3B42V7 }\end{array}$ \\
\hline$E_{\mathrm{NS}}$ & 0.716 & 0.783 & 0.637 & 0.770 \\
\hline$R^{2}$ & 0.788 & 0.801 & 0.725 & 0.747 \\
\hline PBIAS (\%) & -17.875 & -9.475 & -19.642 & -11.213 \\
\hline PEPF (\%) & 3.875 & 6.687 & -7.451 & 7.643 \\
\hline RVE (\%) & 7.658 & 8.875 & 9.745 & 9.354 \\
\hline
\end{tabular}

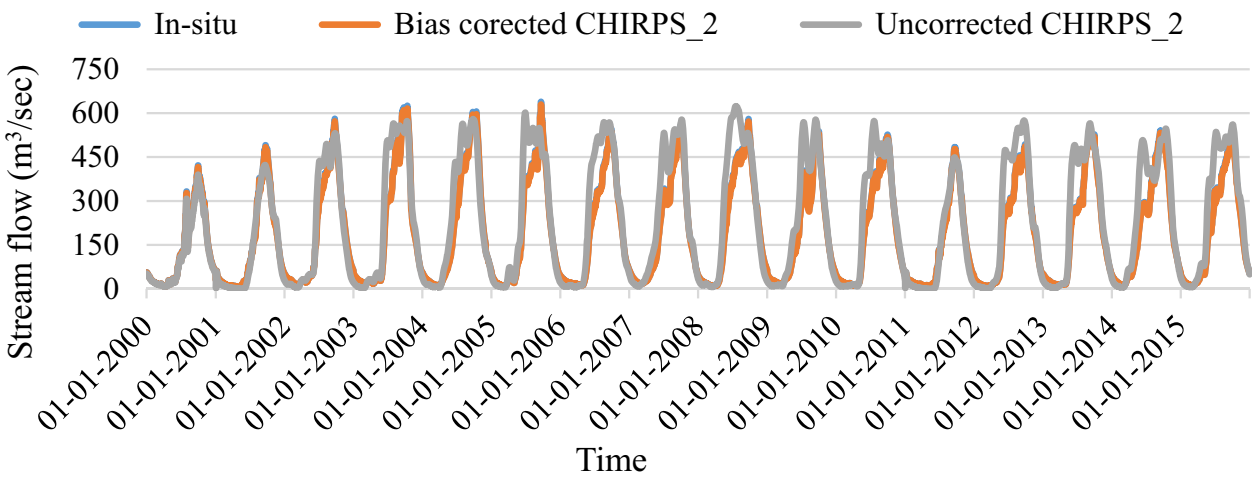

considered in the simulation to investigate the effect of bias correction.

According to the results from the sensitivity analysis using in situ and satellite rainfall data, nine major parameters were selected based on their percentage of sensitivity, including the parameter that was imported from the model, like curve number and lag time. From those used sensitive parameters lag time and Muskingum $\mathrm{k}$, $\mathrm{x}$, were the most sensitive parameters, whereas number of subreach was the least sensitive parameters for the study area.

Daily timescale calibration and validation results over the study area show good performance with $E_{\mathrm{NS}} R^{2}$, PBIAS (\%), PEPF (\%) and RVE (\%), 0.843, 0.954, - 14.648\%, 3.634\%, $5.557 \%$, respectively, for calibration and 0.791 . 0.952 , $-19.638 \%,-6.346 \%$ and $6.634 \%$, respectively, for validation. Hence, the calibrated and validated model parameter can be used for simulation of stream flow in the study area.

Calibration and validation results over the study area were satisfactory when CHIRPS_2 satellite precipitation estimates used with $E_{\mathrm{NS}}, R^{2}$, PBIAS, PEPF and RVE, of $0.695,0.777,-18.425 \%, 4.042 \%, 7.893 \%$, respectively, for calibration and $0.513,0.704,-21.467 \%,-6.075 \%$ and $8.562 \%$, respectively, for validation periods.

The results obtained during calibration and validation of TMPA_3B42v7 satellite rainfall estimates show better than results of CHIRPS_2 estimates. Calibration and validation of TMPA_3B42v7 is also satisfactory with $E_{\mathrm{NS}}$, $R^{2}$, PBIAS, PEPF and RVE, of $0.755,0.786,-11.325 \%$,
$7.335 \%, 9.893 \%$, respectively, for calibration and 0.714 , $0.705,-17.357 \%,-5.075 \%$ and 10 , respectively, for validation period.

Additionally, low HEC-HMS model performance was observed in the study area when it was calibrated and validated with CHIRPS_2 satellite precipitation products than TMPA-3B42v7 satellite precipitation products. This might be because the topography of the area is characterized with rugged landscapes having mostly higher elevation areas.

Subsequently, TMPA-3B42v7 satellite rainfall estimates have good capabilities in capturing precipitation values in high elevation areas than CHIRPS_2 satellite precipitation products which is slightly affected by elevation difference. Comparatively, low performance of HEC-HMS model was resulted for the study area when satellite precipitation estimates are used for calibration and validation instead of using in situ rainfall products.

CHIRPS_2 and TMPA_3B42v7 satellite rainfall data showed overestimation and underestimation of the simulated stream flow due to random and systematic errors though its simulation results were captured the shape of observed stream flow hydrograph. When the model calibrated and validated with bias-corrected satellite precipitation estimates its performance had significantly increased. However, the model performance of stream flow simulation using these bias-corrected satellite precipitation estimates were still lower than simulation result of in situ precipitation products. 
Open Access This article is licensed under a Creative Commons Attribution 4.0 International License, which permits use, sharing, adaptation, distribution and reproduction in any medium or format, as long as you give appropriate credit to the original author(s) and the source, provide a link to the Creative Commons licence, and indicate if changes were made. The images or other third party material in this article are included in the article's Creative Commons licence, unless indicated otherwise in a credit line to the material. If material is not included in the article's Creative Commons licence and your intended use is not permitted by statutory regulation or exceeds the permitted use, you will need to obtain permission directly from the copyright holder. To view a copy of this licence, visit http://creativecommons.org/licenses/by/4.0/.

\section{References}

Alemohammed SH, McColl KA, Konings AG, Entekhabi D, Stoffelen A (2015) Characterization of precipitation product errors across the United State using multiplicative triple collection. Hydrol Earth Syst Sci 19:3489-3503

Ambaw A (2016) Using satellite-based precipitation estimates for runoff modelling with the REW approach: the case of Upper Gilgel Abay catchment, M.Sc. thesis

Ayehu GT, Tadesse T, Gessesse B, Dinku T (2017) Validation of new satellite rainfall products over the Upper Blue Nile Basin, Ethiopia. Atmos. Meas. Tech 10:15-20. https://doi.org/10.5194/ amt-2017-294

Bayissa Y, Tadesse T, Demisse G, Shiferaw A (2017) Evaluation of satellite-based rainfall estimates and application to monitor meteorological drought for the Upper Blue Nile Basin, Ethiopia. Remote Sens. 9:669. https://doi.org/10.3390/rs9070669

Biemans HG (2012) Water constraints on future food production. Wageningen University, Wageningen, The Netherlands

Bigiarini M, Nauditt A, Birkel C, Verbist K, Ribbe L (2017) Temporal and spatial evaluation of satellite based rainfall estimates across the complex topographical and climatic gradients of Chile. Hydrol Earth Syst Sci 21:1295-1320

Chen Z, Chen JM, Zhang S, Zheng X, Ju W, Mo G, Lu X (2013) Optimization of terrestrial ecosystem model parameters. J Geophys Res-Bio Geosci. https://doi.org/10.1002/2016JG003716

Climate Hazard Group (2016) CHIRPSv2.0. Retrieved from Retrieved December, 8, 2017, from, http://chg.ucsb.edu/data/chirps/. Accessed 1 July 2016

Duan Z, Liu J, Tuo Y, Chiogna G, Disse M (2016) Evaluation of eight high spatial resolution gridded precipitation products in Adige Basin (Italy) at multiple temporal and spatial scales. Sci Total Environ 573:1536-1553

Duan Z, Gao H, Tan M (2017) Extreme precipitation and floods: monitoring modelling, and forecasting. J Adv Meteorol 10:15-20. https ://doi.org/10.1155/2017/935069

Funk C, Peterson P, Landsfeld M, Pedreros D, Verdin J, Shukla S (2015) The climate hazards infrared rainfall with stations-a new environmental record for monitoring extreme. ScientificData 2:1-12. https://doi.org/10.1038/sdata.2015.66

Goswami F (2005) Evaluation of model performance ability for hydrologic models: comparison with multilevel expert calibration. J Hydrol Eng 4(2):135-143

Habib E, Haile AT, Sazib N, Zhang Y, Rientjes T (2014) Effect of bias correction of satellite-rainfall estimates on runoff simulations at the source of the Upper Blue Nile. Remote Sens 6(7):6688-6708

Haile AT, Rientjes THM, Gieske ASM (2009) Rainfall variability over mountainous and adjacent lake areas: the case of Lake Tana basin at the source of the Blue Nile River. J Appl Meteorol Climatol 48:1696-1771
Hann CT (2002) Statistical methods in hydrology, 2nd edn. Iowa state press, Iowa, p 496

Hessels TM (2015) Comparison and validation of several open access remotely sensed rainfall products for the Nile basin. M.Sc. thesis, University of Delft, Netherlands

Kidd C, Huffman G (2011) Global precipitation measurement. J Met Appl 18:334-353

Leander R, Buishand Z (2007) Resampling of regional climate model output for the simulation extreme river flows. J Hydrometeorol 332:487-496. https://doi.org/10.1016/j.jhydrol.2006.08.00

Liu J, Zhu AX, Liu Y, Zhu T, Qin CZ (2014) A layered approach to parallel computing for spatially distributed hydrological modeling. Environ Model Softw 51:221-227

Lopez O, Houborg R, Mccabe MF (2017) Evaluating the hydrological consistency of evaporation products using satellite-based gravity and rainfall data. J Hydro Earth Syst Sci 21:323-343. https://doi. org/10.5194/hess-21-323

Moriasi PJ (2007) Model evaluation guidelines for systematic quantification of accuracy in watershed simulations. Am Soc Agric Biol Eng 50(3):850-900

Narjary B, Kamra S (2013) Impact of climatic variability on groundwater resources in fresh ground water region of Haryana. Climate change impact on salt affected soils and their crop productivity

Pineda RV, Demaria EMC, Valdes GB, Wi S, Capdevila AS (2016) Bias correction of daily satellite based rainfall estimates for hydrologic forecasting in the Upper Zambezi, Africa. Earth Syst Sci. https://doi.org/10.5194/hess-2016-473

Santhi C, Arnold J, Williams J, Dugas J, Srinivasan (2001) Validation of the SWAT model. J Am Water Resour Assoc 37(5):1169-1188

Stage F, Xavier A, Zola RP, Hussain Y, Timouk F, Garnier J, Bonnet MP (2017) Comparative assessments of the latest GPM mission's spatially enhanced satellite rainfall products over the main Bolivian watersheds. J Remote Sens 9:369

Tesfaye G, Tadesse T, Gessesse B, Dinku T (2017) Validation of new satellite precipitation products over the upper Blue Nile Basin. Atmos Meas Tech, Ethiopia. https://doi.org/10.5194/ amt-2017-294

USACE (2008) Hydrologic modeling system HEC-HMS, technical reference manual. US Army Corps of Engineers. Hydrologic Engineering Center, St. Davis

Vrgut J, Diks H, Gupta W, Bouten J. Verstranten M (2005) Improved treatment of uncertainty in hydrologic modeling combining the strengths of global optimization and data assimilation. Water Resour Res 41(1)

Xie PP, Xiong AY (2011) A conceptual model for constructing highresolution gauge satellite merged precipitation analyses. J. Geophys Res-Atmos 116:1-14

Yong B, Hong Y, Ren LK, Gourley JJ, Huffman GJ, Chen X, Wang W, Khan SI (2012) Assessment of evolving TRMM based multi-satellite real-time precipitation estimation methods and their impacts on hydrologic prediction in a high latitude basin. J Geophys Res Atmos 117(D9)

Zhang J, Qi Y, Langston C, Kaney B, Howard K (2014) A Real-Time algorithm for merging radar QPEs with rain gauge observations and orographic precipitation climatology. J Hydrometeorol 15:1520. https://doi.org/10.1175/jhm-d-13

Publisher's Note Springer Nature remains neutral with regard to jurisdictional claims in published maps and institutional affiliations. 